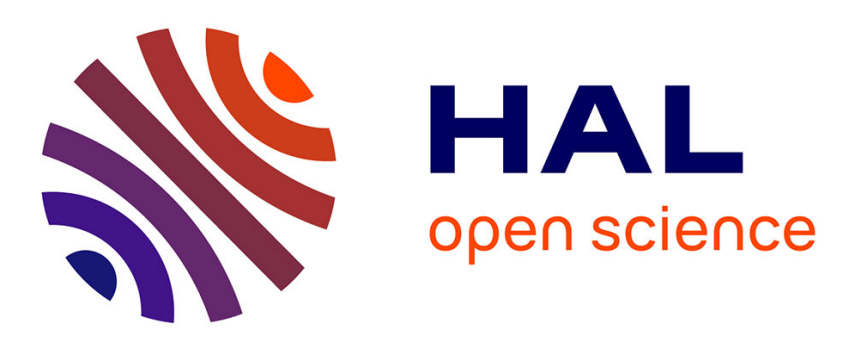

\title{
Nanoparticles as contrast agents for brain nuclear magnetic resonance imaging in Alzheimer's disease diagnosis
}

David Azria, Sébastien Blanquer, Jean-Michel Verdier, Emmanuel Belamie

\section{- To cite this version:}

David Azria, Sébastien Blanquer, Jean-Michel Verdier, Emmanuel Belamie. Nanoparticles as contrast agents for brain nuclear magnetic resonance imaging in Alzheimer's disease diagnosis. Journal of materials chemistry B, 2017, 5 (35), pp.7216-7237. 10.1039/C7TB01599B . hal-02007861

\section{HAL Id: hal-02007861 \\ https://hal.umontpellier.fr/hal-02007861}

Submitted on 10 Dec 2020

HAL is a multi-disciplinary open access archive for the deposit and dissemination of scientific research documents, whether they are published or not. The documents may come from teaching and research institutions in France or abroad, or from public or private research centers.
L'archive ouverte pluridisciplinaire HAL, est destinée au dépôt et à la diffusion de documents scientifiques de niveau recherche, publiés ou non, émanant des établissements d'enseignement et de recherche français ou étrangers, des laboratoires publics ou privés. 
Check for updates

Cite this: J. Mater. Chem. B, 2017, 5, 7216

Received 12th June 2017 Accepted 28th July 2017

DOI: $10.1039 / c 7 t b 01599 b$

rsc.li/materials-b

\title{
Nanoparticles as contrast agents for brain nuclear magnetic resonance imaging in Alzheimer's disease diagnosis
}

\author{
David Azria, (DD ${ }^{\text {ab }}$ Sébastien Blanquer, ${ }^{a}$ Jean-Michel Verdier ${ }^{\mathrm{bc}}$ and \\ Emmanuel Belamie (D)*ab
}

\begin{abstract}
Nuclear Magnetic Resonance Imaging (MRI) of amyloid plaques is a powerful non-invasive approach for the early and accurate diagnosis of Alzheimer's disease (AD) along with clinical observations of behavioral changes and cognitive impairment. The present article aims at giving a critical and comprehensive review of recent advances in the development of nanoparticle-based contrast agents for brain MRI. Nanoparticles considered for the MRI of AD must comply with a highly stringent set of requirements including low toxicity and the ability to cross the blood-brain-barrier. In addition, to reach an optimal signal-to-noise ratio, they must exhibit a specific ability to target amyloid plaques, which can be achieved by grafting antibodies, peptides or small molecules. Finally, we propose to consider new directions for the future of MRI in the context of Alzheimer's disease, in particular by enhancing the performances of contrast agents and by including therapeutic functionalities following a theranostic strategy.
\end{abstract}

\section{Introduction}

Alzheimer's disease (AD) is the most common neurodegenerative disease and accounts for $60-80 \%$ of all dementia with more than 33 million people affected in 2011. ${ }^{1}$ Brookmeyer et al. estimated that, in 2050, 1/85 people are susceptible to contracting $\mathrm{AD}$, which represents more than 100 million people worldwide. ${ }^{2}$ The G7 countries share more than $60 \%$ of dementias' global costs with a prevalence of less than $30 \%$. $^{3}$ Despite reports indicating a decline in the incidence of Alzheimer's disease in high income countries (Europe and USA), the overall increase in life expectancy should result in a worldwide increase in its prevalence rate. ${ }^{4,5}$ The costs of dementia were reported to be approx. 600 billion US dollars worldwide in $2010,{ }^{6}$ more than 800 billion in 2015 and are expected to reach 1 trillion US dollars in $2030,{ }^{3}$ which illustrates the strong economic and social impact of AD.

From a clinical point of view, Alzheimer's disease is characterized by neuronal degeneration that leads to cognitive decline and behavioral disorders. ${ }^{7}$ The main risk factor to develop $\mathrm{AD}$ is ageing, but other risk factors like familial history,

\footnotetext{
${ }^{a}$ Institut Charles Gerhardt Montpellier, UMR 5253 CNRS-UM-ENSCM, Equipe Matériaux Avancés pour la Catalyse et la Santé, 8 rue de l'Ecole Normale, 34296 Montpellier Cedex 5, France.E-mail: Emmanuel.Belamie@enscm.fr

${ }^{b}$ Ecole Pratique des Hautes Etudes, PSL Research University, 75014 Paris, France

${ }^{c}$ INSERM 1198 - Unité mixte UM - EPHE, Place Eugène Bataillon-CC105,

34095 Montpellier Cedex 5, France
}

head trauma, cardiovascular disorders and cholesterol disorders are believed to contribute to $\mathrm{AD},{ }^{8,9}$ as well as the APOE genotype in late onset sporadic forms. ${ }^{10}$ The symptoms of $\mathrm{AD}$ were initially described by Alois Alzheimer at the beginning of the XXth century. Alzheimer reported for the first-time postmortem observations of amyloid plaques and neurofibrillary tangles in the brain of one of his patients that he had earlier diagnosed with cognitive disorder. The correlation between these two molecular features of the pathology is still not completely elucidated. ${ }^{11}$ Amyloid plaques are more suited for the in vivo diagnosis of $\mathrm{AD}$ by MRI because they are comprised of extracellular deposits of amyloid $(\mathrm{A} \beta)$ peptide, while neurofibrillary tangles are less accessible intracellular aggregates of hyperphosphorylated tau protein. ${ }^{12}$ It should be noted that other pathologies such as dementia with Lewy bodies or Pick's disease are also characterized by the presence of amyloid aggregates. ${ }^{7,13,14}$

Amyloid deposits are due to the aggregation of $A \beta$ peptides $^{15,16}$ produced by the amyloidogenic processing of the transmembrane Amyloid Precursor Protein (APP) ${ }^{17,18}$ (Fig. 1). The site of enzymatic cleavage in the extracellular domain discriminates between non-amyloidogenic ( $\alpha$-secretase) and amyloid pathways ( $\beta$-secretase). This largely determines the risk to develop $\mathrm{AD}^{19}$ since processing of APP by $\beta$-secretase followed by $\gamma$-secretase results in the production of $\mathrm{A} \beta$ peptides and thus amyloid plaques (Fig. 1). Amyloid fibrils are comprised of $A \beta$ peptides aggregated in $\beta$ strands arranged in a double layer $\beta$-sheet from which water is excluded. Protofilaments are composed of twisted $\beta$-sheets that assemble together to form amyloid fibrils (Fig. 2). ${ }^{20}$ 


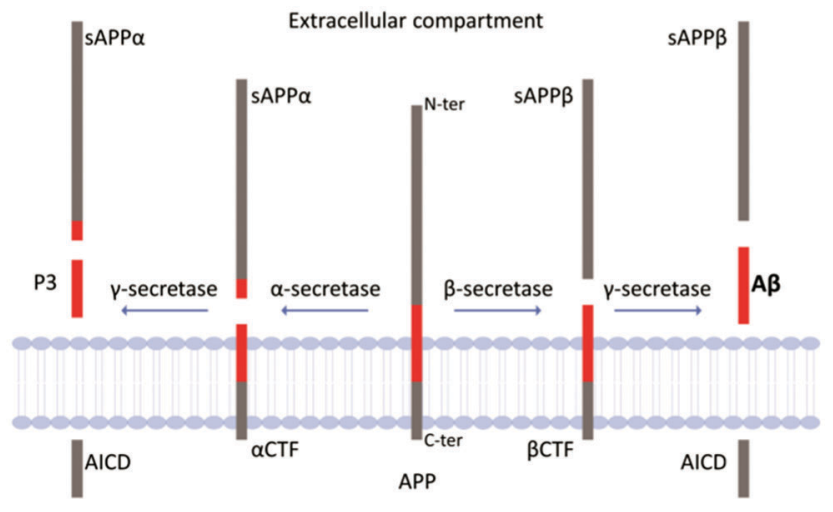

Intracellular compartment

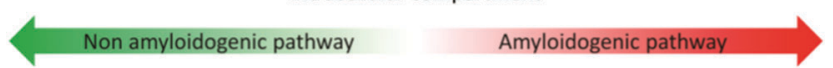

Fig. 1 Schematic representation of APP processing. APP: amyloid precursor protein; $A \beta$ : peptide formed by the processing of the APP by the succession of $\beta$ - and $\gamma$-secretase; P3: peptide formed by successive $\alpha$-and $\gamma$-secretase cleavage of APP; sAPP $\alpha / \beta$ : soluble APP $\alpha / \beta ; \alpha / \beta C T F: \alpha / \beta$ $C$-terminal fragment; AICD: APP intra-cellular domain; $\alpha / \beta / \gamma$ secretase: enzymes able to cleave the APP at specific locations.
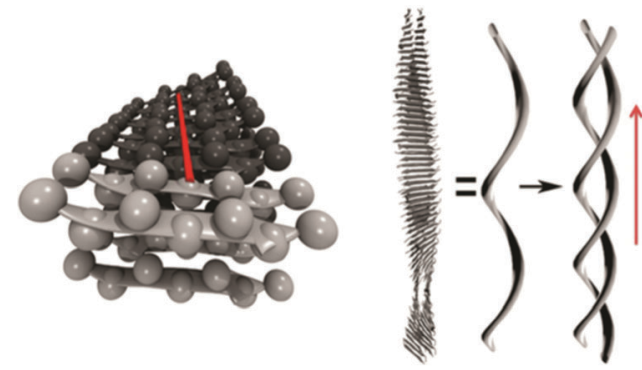

Fig. 2 Schematic representation of amyloid fibrils. Adapted with permission from ref. 20. Copyright (2013) American Chemical Society.

Eight isoforms of the Amyloid Precursor Protein have been described, ranging from 365 to 770 amino acids. ${ }^{21}$ Among the 3 major isoforms of APP (APP695, APP751 and APP770), ${ }^{22}$ APP695 was widely recognized to be the most abundant in the brain. $^{23-28}$ Following cleavage by $\beta$-secretases, the $\gamma$-secretase action at several possible sites (Fig. 1) generates $\mathrm{A} \beta$ peptides from 39 to 43 amino acids. The two major $A \beta$ peptide variants in the amyloidogenic pathway initiated by the $\beta$-secretase cleavage are $A \beta_{1-40}$ and $A \beta_{1-42}$, and the latter is the most insoluble. ${ }^{29-31}$ Physiologically, $A \beta_{1-40}$ is by far the most abundant in the brain, while $A \beta_{1-42}$ tends to reach a higher concentration in $\mathrm{AD}$ brains than in normal ones ${ }^{31-33}$ and exhibits more toxicity than $\mathrm{A} \beta_{1-40}{ }^{34}$ Although monomeric $\mathrm{A} \beta$ peptides (1-40 and 1-42) were shown to protect neurons from oxidative damage, ${ }^{35,36}$ $\mathrm{A} \beta$ peptide aggregates generate oxidative stress ${ }^{37}$ leading to neuronal death by apoptosis. ${ }^{38}$ A recent study demonstrated that contact is required between neurons and $A \beta$ aggregates to induce neurodegeneration. ${ }^{39}$ Although treatments for $\mathrm{AD}$ are only symptomatic and produce moderate effects, early diagnosis including asymptomatic phases was recently shown to increase their benefits. ${ }^{40}$ Several biomarkers can be used in combination to facilitate the diagnosis of Alzheimer's disease. ${ }^{41,42}$ This includes the quantification of markers in biological fluids, and in particular the cerebro-spinal fluid (CSF) analysis of A $\beta$ and Tau level ratios. ${ }^{41,42}$ Recently, in vitro diagnosis methods have been developed based on the detection of $A \beta$ peptide oligomers in the CSF by ELISA ${ }^{43}$ and in the plasma by immunomagnetic reduction assay. ${ }^{44}$ Besides, neuroimaging has gained a pivotal role in $\mathrm{AD}$ diagnosis, providing valuable biomarkers based on well-proven, widely used technologies such as Computed Tomography (CT), Positron Emission Tomoscintigraphy (PET) ${ }^{45}$ and Nuclear Magnetic Resonance Imaging (NMRI, or more simply MRI). It is not the aim of the present review to weigh the respective advantages and drawbacks of these complementary imaging techniques, ${ }^{46}$ which should actually be combined to achieve more reliable diagnosis. However, the limitations of the currently available methods ${ }^{47}$ and the need for multimodal approaches for early diagnosis of $\mathrm{AD}$ have raised interest for MRI as a non-invasive and sensitive technique. ${ }^{48}$

In this article, we give a comprehensive overview of recent developments in the design of nanoparticles (NPs) as MRI contrast agents for the detection of amyloid plaques. The motivations can be either the early diagnosis of $\mathrm{AD}$ or more fundamental work involving the detection of early stages of the disease and follow-up of the treatments. After briefly presenting the main MRI contrast agents investigated to date, general considerations are given regarding the stability and trafficking of NPs through the body. We then focus on crucial features more specifically related to the imaging of amyloid plaques, notably the crossing of the blood-brain barrier (BBB), the targeting of plaques and the possible toxicity of the NPs. Most importantly, this article aims at highlighting major advances in all these aspects and recapitulates recent approaches developed in other medical areas and amenable to AD diagnosis. Finally, a discussion is proposed about insights into future improvements and fate of MRI as a valuable tool for AD diagnosis and possibly theranostics.

\section{General principles and requirements for MRI contrast agents}

MRI is a non-invasive technique, very powerful and appropriate to image inaccessible parts of the body and thus potentially suited for the detection of amyloid plaques inside the brain. Importantly, exposure to strong magnetic fields used for MRI is considered globally safe ${ }^{49}$ with no significant genotoxicity. ${ }^{50}$

MRI is mostly based on the nuclear magnetic resonance of protons extremely abundant in living organisms, notably in the form of water. In rare cases, other nuclei such as ${ }^{13} \mathrm{C},{ }^{31} \mathrm{P}$ or ${ }^{23} \mathrm{Na}$ have been used for detection by MRI. ${ }^{51-53}$ A strong static magnetic field is first used to align the proton nuclear magnetic moments, which are then selectively deflected in the transversal plane upon application of a radio-frequency pulse. The time necessary for the magnetic moments to come back to the original longitudinal direction of the static magnetic field is defined as the relaxation time. Two different relaxation times 
can be considered: $T 1$, which corresponds to the longitudinal recovery, and $T 2$, which is the transversal decay. Both relaxation times are the source of contrast in MRI and are often characterized by relaxivities $r 1(1 / T 1)$ and $r 2(1 / T 2)$.

The amyloid plaques are the biological objects targeted for early MRI diagnosis of AD. The targeting of these structures is based on their molecular recognition by either synthetic amyloid peptides or analogs, small molecules selected for their strong specific affinity, or antibodies.

MRI detection of neuritic plaques without contrast agents was reported years ago on formalin-fixed human brain specimens ${ }^{54}$ and then on APP/PS1 mice, both ex vivo ${ }^{55}$ and in vivo. ${ }^{56,57}$ Without contrast agents, long acquisition times are required, which is hardly compatible with in vivo imaging because of multiple sources of movement such as breathing or heartbeats. To achieve detection of individual plaques in vivo, harsh procedures like cardiorespiratory triggering are required, and yet images remain blurry. In these conditions the resolution is limited to $50 \mu \mathrm{m}$ which typically excludes $80 \%$ of total plaques in an animal model ${ }^{57,58}$ and in humans. ${ }^{59}$ Consequently, the development of efficient contrast agents is a major challenge for the in vivo imaging of amyloid plaques by NMR-based technologies, especially with the aim of early detection.

\subsection{Main contrasting compounds}

Three metallic compounds that bring contrast enhancement have been more particularly investigated in the context of $\mathrm{AD}$ diagnosis: gadolinium (Gd), manganese $(\mathrm{Mn})$ and iron (Fe). Gadolinium is by far the most widely used element to enhance MRI contrast and nine different gadolinium-chelates were approved by the FDA. ${ }^{60}$ Two other contrast agents, not based on gadolinium, but approved by the FDA for intravenous clinical use are iron-oxide nanoparticles Feridex and manganese-chelates Teslascan. ${ }^{61}$ Gadolinium and manganese are usually associated with $T 1$ imaging while iron is principally used for $T 2$ weighted images,${ }^{62}$ but all contrast agents shorten both $T 1$ and $T 2$ and can be used for 71 - and $T 2$-weighted imaging. ${ }^{63}$ Briefly, the radiofrequency pulse applied during MRI acquisition gives energy to protons, and $T 1$ contrast agents shorten the longitudinal recovery by enhancing the energy transfer from protons to $\mathrm{Gd} / \mathrm{Mn}$ present in the contrast agent. Only protons near the contrast agent can be discharged of their energy, and the most impacted protons are typically those from the surrounding water. Water protons in tissues containing the contrast agent can relax more rapidly along the longitudinal direction. This results in an increased signal compared to other tissues devoid of the contrast agent, hence brighter spots in $T 1$-weighted images. $T 2$ contrast agents (iron oxide) locally disturb the magnetic field. Protons in the vicinity of $T 2$ contrast agents dephase faster from the radiofrequency pulse than other protons, thus increasing the transverse decay rate. The water protons in a tissue containing the contrast agent produce a signal less intense than from surrounding tissues, which generates darker spots in $T 2$-weigthed images. ${ }^{64,65}$

Gadolinium, an element of the lanthanide series, has been used in research as a contrast agent in MRI for at least three decades. ${ }^{66}$ As mentioned previously, Gd usually enhances T1-weighted images, due to its paramagnetic properties. Gadolinium ions $\left(\mathrm{Gd}^{3+}\right)$ are highly toxic and must be chelated to be used in vivo, the stability of the complex being a key parameter for the safety of Gd-based drugs. Among the many complexes obtained with Gd, ${ }^{67}$ Gd-DTPA (diethylenetriaminepentaacetic acid, DTPA) is in widespread use in clinic as a MRI contrast agent. The Magnevist ${ }^{\mathbb{R}}$ contrast agent composed of Gd-DTPA has been approved by the FDA since 1988. In the following 11 years after this approval, estimations were reported that 30 metric tons of gadolinium contrast agent were injected for diagnosis. ${ }^{62}$ Petiet et al. demonstrated the capacity of non-targeted gadolinium complexes as MRI contrast agents to detect amyloid plaques in the cortex and hippocampus of transgenic mice, in vitro and in vivo. ${ }^{68}$ Silica-coated gadolinium oxide nanoparticles have been recently reported as a MRI contrast agent in research. ${ }^{69}$ However, the toxicity of Gd ions remains a major issue and prompted investigations with alternative formulations, mostly of iron and manganese, which are already FDA-approved. ${ }^{61}$

Manganese is considered today as the best alternative to gadolinium for the development of MRI $T 1$ contrast agents. Several works have proven that $\mathrm{MnCl}_{2}$ injection allows enhancement of the contrast in the brain. ${ }^{70-72}$ Manganese complexes suffer from relatively high lability ${ }^{73}$ and current investigations aim at improving their stability. ${ }^{74}$ Manganese oxide nanoparticles (MON) exhibit much higher stability in water than Mn chelates and have been studied for brain tumor MRI. ${ }^{75}$ Because manganese chelates or NP are $T 1$ contrast agents, close interaction with water is essential to shorten the relaxivity and enhance signal contrast. To favor water-surface interactions, materials with high specific surface area have been investigated, either by downsizing the particles or by creating hollow nanoparticles called "HMON". ${ }^{76,77}$

Magnetic iron oxide nanoparticles are widely synthesized, in the form of maghemite $\left(\gamma-\mathrm{Fe}_{2} \mathrm{O}_{3}\right)$ or magnetite $\left(\mathrm{Fe}_{3} \mathrm{O}_{4}\right)^{78}$ for use in nanomedicine. ${ }^{79}$ More specifically, super-paramagnetic ironoxide nanoparticles (SPIONs) are extensively studied for MRI application. ${ }^{80}$ The presence of amyloid deposits in the mouse and rat brain has been successfully identified ex vivo with T2-weighted MRI using SPIONs. ${ }^{81-83}$ Interestingly, biogenic magnetite has been detected in the human body ${ }^{84}$ with increasing occurrence upon aging and AD development. ${ }^{85,86}$ Moreover, it was discovered that some amyloid deposits contain iron, exhibiting higher contrast in MRI. ${ }^{87,88}$ Most importantly, Dobson et al. have shown that cellular viability is not affected by MRI at 9.4 Tesla in the presence of synthetic magnetite particles of 100 and $500 \mathrm{~nm}$ in diameter, ${ }^{89}$ which suggests that iron oxide particles should be safe for brain MRI.

Nanoparticles (NPs) made out of metals (iron, manganese) or lanthanides (gadolinium) effectively enhance contrast in MRI. ${ }^{90,91}$ Yet, their safe and efficient use raises several important issues (Fig. 3), which can be partly addressed with nanotechnologybased solutions. ${ }^{92}$ Metal-oxide nanoparticles are already available for therapeutic use in the USA. For instance, in 2009 the FDA authorized ferumoxytol (Feraheme ${ }^{\circledR}$ ) a drug based on iron-oxide 


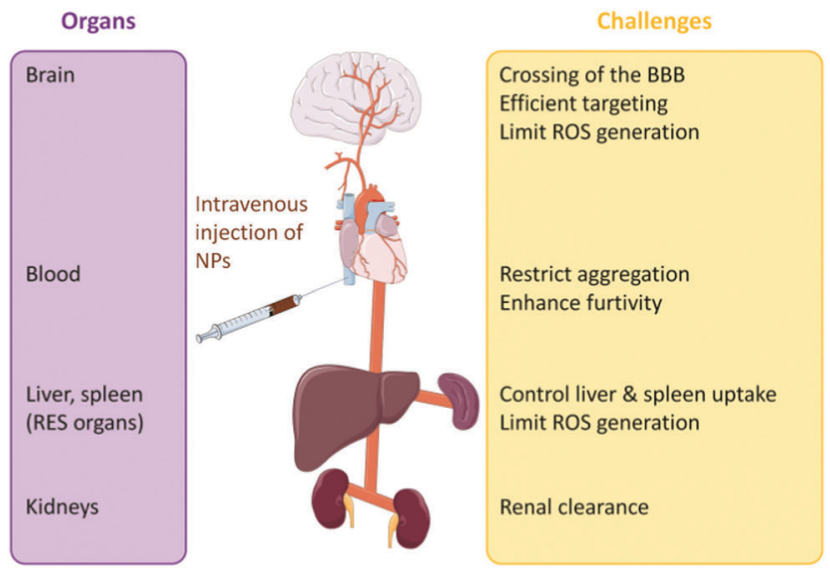

Fig. 3 Scheme of the main challenges in the design and use of nanoparticles in vivo with respect to interactions with several organs and biological barriers.

nanoparticles used to treat chronic kidney failure. ${ }^{93,94}$ Of note, the FDA has recently published a warning about the safety of this drug following 79 cases of allergic reaction and 18 reported fatalities. ${ }^{95}$ Other SPIONs, namely ferumoxsil (Lumirem ${ }^{\circledR} /$ Gastromark $^{\circledR}$ ) for oral administration and ferumoxide (Endorem ${ }^{\mathbb{R}} /$ Feridex $^{\mathbb{R}}$ ) for intravenous injection, have received FDA approval but both were discontinued for economic reasons.

Both T1- and T2-weighted MRI have advantages and disadvantages and both are routinely used, often in combination, to image the brain and identify brain pathologies such as tumors. Typically, tumors exhibit dominantly hypointense $T 1$ imaging patterns and predominant $T 2$ hyperintensity. ${ }^{96}$ In the context of AD imaging, high magnetic fields are used (beyond 7 Tesla) to generate high resolution images. This results in lower contrast in T1-weighted MRI, making it less efficient for the detection of amyloid plaques. ${ }^{97,98}$ However, agents like Gd-chelates usually employed as $T 1$ contrast agents also shorten $T 2$ (vide supra) and thus remain useful for $\mathrm{AD}$ by $T 2$-weighted MRI. ${ }^{98,99}$ A very recent study showed that $T 1$-weighted/T2-weighted MRI ratio images might be useful for early detection of $A \beta$ accumulation. ${ }^{100}$

\subsection{Behavior and trafficking of nanoparticles}

Because their target is located in the brain, contrast agents for the MRI of AD should firstly be able to cross the blood-brain barrier, but must also fulfill several other specific requirements. ${ }^{101}$ For instance, when present in the blood compartment, $95 \%$ of nanoparticles accumulate in major organs (spleen, lungs, liver) of the reticulo-endothelial system (RES), leaving only 5\% useful for diagnosis. ${ }^{102}$ It is therefore important to extensively study the spreading route of NPs in the body and their interactions with organs. Besides, this accumulation of contrast agent NPs in several tissues raises the major issue of their toxicity. Conversely, modifying the NPs to extend their blood circulation time, cross the BBB or limit their toxicity influences their relaxivity and thus their efficiency in providing contrast enhancement. ${ }^{103}$ In what follows, we give an overview of recent advances in the design of contrast agents for in vivo brain MRI to enhance their ability to cross the blood-brain barrier (BBB) and to target structures of interest, to extend their half-life in blood and to limit their toxicity.

2.2.1 Colloidal and chemical stability. Biological media are ionic fluids containing many soluble compounds ranging from small ions to large macromolecules, both affecting the NPs' colloidal stability. And when electrostatic repulsions are the main stabilizing forces, the $\mathrm{pH}$ of the media also plays a determinant role. Super-paramagnetic iron-oxide nanoparticles are comprised of iron, either in the ferric state in maghemite $\left(\gamma-\mathrm{Fe}_{2} \mathrm{O}_{3}\right)$ or in the ferrous-ferric state in magnetite $\left(\mathrm{Fe}_{3} \mathrm{O}_{4}: \mathrm{FeO} \cdot \mathrm{Fe}_{2} \mathrm{O}_{3}\right), \gamma \mathrm{Fe}_{2} \mathrm{O}_{3}$ USPIONs being more stable than $\mathrm{Fe}_{3} \mathrm{O}_{4}$-USPIONs. ${ }^{104}$ SPIONs with a nominal size of $6 \mathrm{~nm}$ (TEM) exhibit hydrodynamic diameters of $50 \pm 5$ and $380 \pm 40 \mathrm{~nm}$ in saline conditions at $\mathrm{pH} 4.2-5.6$ for $\gamma \mathrm{Fe}_{2} \mathrm{O}_{3}$-USPIONs and $\mathrm{Fe}_{3} \mathrm{O}_{4}$-USPIONs respectively, thus indicating slight aggregation at acidic $\mathrm{pH}$. An increase in $\mathrm{pH}$ above these values leads to very large aggregates with typical sizes in the 3-5 $\mu \mathrm{m}$ range, revealing destabilization of the colloidal suspension. ${ }^{104}$ Because the state of aggregation is strongly related to the toxic effect of NPs, it is important to assess their effective dimensions in suspension in aqueous media, which can be readily done by combining dynamic light scattering (DLS) with electron microscopy. ${ }^{105,106}$

Proteins are abundant in biological media and often adsorb onto the NP surface. The resulting protein corona becomes the interface between the nanoparticles and their environment ${ }^{107-109}$ and is accountable for the modification of their absorption pathways. ${ }^{110}$ For instance, in saline physiological conditions, $\mathrm{SiO}_{2}$ NPs exhibiting a negatively charged surface are stable but start to aggregate when proteins from fetal calf serum (FCS) are added. In contrast, $\mathrm{SiO}_{2}$ NPs modified to expose a positively charged surface aggregate in saline physiological conditions but are stabilized by FCS proteins. ${ }^{111}$ In blood, gold NPs are reported to be not only in relation with blood proteins but also with blood cells. ${ }^{112}$ Although in vivo characterization of nano-bio interfaces is a delicate task, ${ }^{113}$ a good knowledge of the protein corona formation kinetics, composition and equilibrium properties is crucial to ensure the efficacy of NPs. ${ }^{114}$

To prevent aggregation, nanoparticles are often coated with polymers. This surface coating provides steric stabilization and hampers protein adsorption, resulting in higher stability in physiological conditions and lower toxicity. Among the many biocompatible polymers reported in the literature, PEG and dextran are the most commonly used. ${ }^{115}$ PEG coating of NPs has been widely described to minimizes the body uptakes of NPs without causing any immune interaction, thus allowing for a longer blood circulation time. ${ }^{115,116}$ In the context of targeted cancer treatment, this resulted in higher tumor uptake and finally higher efficiency. ${ }^{102}$ Many studies have highlighted the beneficial effects of PEG on tissue regeneration and repair in the case of Central Nervous System (CNS) trauma. ${ }^{117,118}$ PEGylation of graphene oxide nanoparticles (diameter ranging from 10 to $800 \mathrm{~nm}$ ) was reported to reduce their toxicity and enhance their blood circulation time from 5.35 hours to 6.29 hours after intravenous injection in mice. This coating lowers the retention time and enhances the clearance of NPs in 
the liver, lungs and spleen. ${ }^{119}$ The polymerization of $\operatorname{poly}(n$ butylcyanoacetate) (PBCA) in the presence of PEG led to $100 \mathrm{~nm}$ sized NPs presenting a high resistance to aggregation. These PBCA-PEG NPs were less toxic than uncoated ones to macrophage cell cultures. ${ }^{120}$ This was also observed with manganese ferrite NPs of 6 and $14 \mathrm{~nm}$, whose PEG coating reduces aggregation, enhances blood circulation time and limits their cytotoxicity. ${ }^{121}$ It should be noted that NP processing or posttreatments may impair the properties of the coating. For instance, Shah et al. reported that freeze-drying of PEG-coated NPs resulted in the partial removal of the polymer coating and decrease of the blood retention time by a factor of 15 due to more exposed negative charges. ${ }^{112}$

PEG and dextran have been used to coat SPIONs ${ }^{122}$ and USPIONs $^{123}$ used as contrast agents in MRI. ${ }^{124,125}$ Dextran favors good dispersion of the NPs in water and provides functionalization sites for targeting agents. ${ }^{44}$ Another polysaccharide, chitosan, extracted from fungal cell walls and crustacean exoskeleton ${ }^{126}$ has been successfully used with SPIONs or Gd chelates. ${ }^{127-129}$ Microspheres of chitosan have also been synthesized and loaded with Gd-DTPA with the purpose to serve in gadolinium-based neutron capture therapy. ${ }^{130}$ It was recently reported that composites made of chitosan and iron-oxide nanoparticles with adsorbed Gd-DTPA NPs could be used for dual-weighted $T 1 / T 2$ MRI. ${ }^{131}$ Iron-oxide NPS were also encapsulated into chitosan spheres (SPIONs-CS), with particle size around $120 \mathrm{~nm}$. Such SPIONs-CS showed high resistance to aggregation in solution at $\mathrm{pH} 6$, over 5 months compared to single SPIONs which tended to aggregate only few hours after synthesis, and were used to obtain $T 2$-weighted images. ${ }^{132}$ Others recently reported the encapsulation of SPIONs within alginate hydrogels, which allowed for efficient T2-weighted MR imaging of tumors. ${ }^{133}$

The nature and thickness of the coating relative to the NP core size influences the relaxivity of the contrast agents. ${ }^{134}$ For instance, optimum $T 2$ relaxivity was achieved by coating $5 \mathrm{~nm}$ SPIONs with PEG $550 \mathrm{~g} \mathrm{~mol}^{-1}$ while PEG $1000 \mathrm{~g} \mathrm{~mol}^{-1}$ gave better results for $14 \mathrm{~nm}$ SPIONs. ${ }^{135}$ Another recent study also suggested an optimum relation between the size of magnetic crystal domains, polymer size (PEG $300 \mathrm{~g} \mathrm{~mol}^{-1}$ or $600 \mathrm{~g} \mathrm{~mol}^{-1}$ ) and coating thickness to enhance relaxivity. ${ }^{136}$ Other polysaccharides and synthetic polymers can provide specific properties for the coating of NPs used in different areas of imaging and theranostics, as recently reviewed. ${ }^{137,138}$

2.2.2 Biodistribution and elimination of nanoparticles. Long blood circulation times are initially required because the nanoparticles must have an opportunity to cross the BBB and reach their target (amyloid plaques). However, the contrast agents must be eliminated after imaging to avoid toxic effects due to their accumulation. The main routes for the elimination of drugs and impurities from blood are renal clearance and hepatobiliary uptake followed by excretion.

In kidneys, the filtration units are glomeruli whose functional pore size for clearance is approx. 4.5-5 $\mathrm{nm}$. Particles with hydrodynamic diameters larger than $8 \mathrm{~nm}$ are not filtered, although the presence of charges also affects renal filtration: positively charged NPs are more easily filtered, then neutral and finally anionic NPs. ${ }^{139,140}$ PEG-coating can be used to increase the hydrodynamic diameter and thus limit renal filtration. In the more complex hepatobiliary system, liver Kupffer cells are involved in the removal of substances from the blood, NPs in particular. ${ }^{141}$ The liver uptake from blood is quite fast, while biliary excretion is slower, resulting in the retention of NPs. ${ }^{139,142,143}$ Gold NPs with sizes of 5 and $25 \mathrm{~nm}$ and stabilized with citrate do not exhibit toxicity when administered to New Zealand White rabbits at a dose of $1 \mathrm{mg} \mathrm{kg}{ }^{-1}$. The larger $25 \mathrm{~nm}$ NPs lead to an increase in the number of white blood cells, but no renal, hepatic, pulmonary or other organ toxicity was reported after clinico-pathological examination. The NPs are evenly distributed between spleen and liver, kidneys and lung to a smaller extent. Larger NPs appear to be more concentrated than smaller ones, due to the renal excretion of $5 \mathrm{~nm}$ sized NPs. ${ }^{144}$ Smaller Gold NPs of 1.4 and $18 \mathrm{~nm}$ exhibit two different distributions. While $1.4 \mathrm{~nm}$ NPs spread relatively homogeneously in the body of rats with a high amount in the liver (50\%), kidneys and urine (14\%), gastrointestinal tract (GIT) and feces (5\%), $18 \mathrm{~nm}$ NPs are mainly distributed in the liver $(>90 \%)$, spleen $(2 \%)$ and GIT and feces (0.5\%). No $18 \mathrm{~nm}$ NPs are found in urine, which confirms the inability of kidneys to proceed to renal excretion of NPs with a size higher than 5-6 nm. ${ }^{145}$

Choi et al. proposed that NPs designed for clinical use should fulfill three requirements to satisfy safety considerations: (1) their final hydrodynamic diameter should be smaller than $5.5 \mathrm{~nm}$ to allow for full clearance from the body; (2) they should be elaborated with fully non-toxic molecules in NPs; (3) they should degrade physiologically to clearable substances. ${ }^{142}$ In several ways, these considerations apply to the design of NPs destined to be used as MRI contrast agents.

\section{Obstacles and strategies to reach amyloid plaques}

\subsection{Crossing the blood-brain barrier (BBB)}

Ideally, injection of contrast agents should be intravenous, ${ }^{146}$ which implies passing from the blood to the brain compartment. Fig. 4 is a schematic representation of the BBB with the main cellular components and illustrates the receptor-based crossing of the BBB by contrast agent NPs. The blood-brain barrier (BBB) maintains the CNS homeostasis and prevents the intrusion of pathogens by strictly controlling exchanges between brain and blood. It is comprised of endothelial cells bound together by tight junctions, with pericytes surrounding them, then astrocyte foot processes, microglia and neurons. ${ }^{147,148}$ Flattened endothelial cells exhibit a thickness of $c a .500 \mathrm{~nm}$ and control the passage of molecules and macromolecules, through either adsorptive- (AMT) or receptor-mediated transcytosis (RMT). It was reported that caveolae able to cross the endothelial layer have limited sizes in the $50-80 \mathrm{~nm}$ range, ${ }^{149}$ which thus limits the overall size of agents intended to reach the brain. Endothelial cells express receptors for transferrin, ${ }^{150}$ ApoE and related molecules, ${ }^{151}$ amyloid peptide $\mathrm{A} \beta^{152-154}$ 


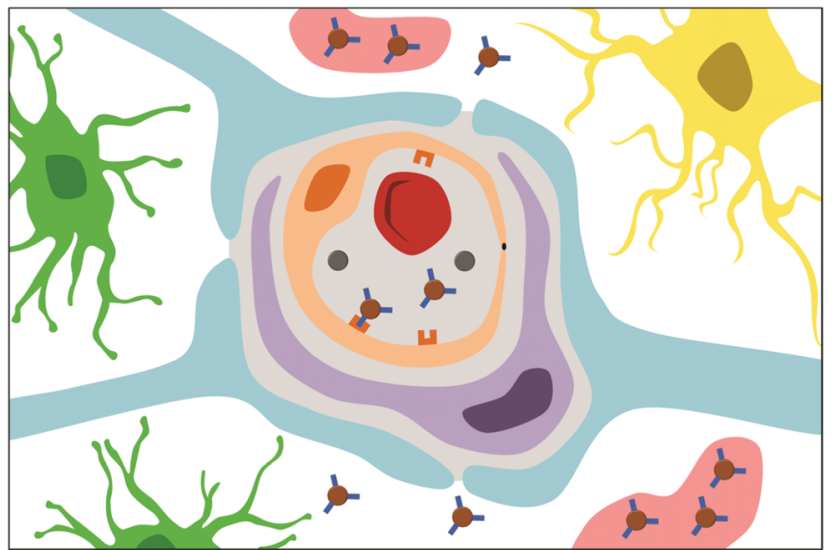

Fig. 4 Schematic representation of the blood-brain barrier crossing by nanoparticles. Endothelial cells (orange cell) form an impervious barrier due to tight junctions. Other components of the blood-brain barrier are pericytes (purple cells) that envelop endothelial cells and then astrocyte foot processes (in blue). Functionalized nanoparticles (red brown spheres with blue spikes) located in blood vessels with red blood cells (red cell) are able to cross endothelial cells through receptors (orange U-shape) unlike non-functionalized NPs (grey spheres). NPs able to pass the BBB can then spread in the brain among microglia (green cells) and neurons (yellow cell) and concentrate at their target, the amyloid deposits (pink shape).

and others. These receptors are obvious targets to trigger the crossing of the BBB. In $\mathrm{AD}$, vessels surrounded by amyloid deposits are defective, ${ }^{155,156}$ and the $\mathrm{BBB}$ exhibited higher permeability to endogenous albumin. ${ }^{157}$ BBB permeability can be affected by vascular dementia ${ }^{158}$ and growing evidence shows that $\mathrm{AD}$ and $\mathrm{BBB}$ defects occur together. Different studies in animal models of $\mathrm{AD}$ have yielded contrasting conclusions regarding the integrity of the BBB as assessed by the passage ${ }^{82,159}$ or retention of contrast agents. ${ }^{83,160}$ When released from the blood compartment, contrast agents diffuse into the tortuous brain extracellular compartment. This compartment accounts for about $20 \%$ of the brain volume, although the spacing between adjacent cells is estimated to be only $20-60 \mathrm{~nm}$ on average. ${ }^{161,162}$ Nance et al. showed that $200 \mathrm{~nm}$ NPs with a dense PEG-coating are able to diffuse between human brain cells, while only $100 \mathrm{~nm}$ NPs can do so in the rat brain. ${ }^{163}$ The authors estimated that few pores allow for the passage of $200 \mathrm{~nm}$ molecules in the human brain, but more than $25 \%$ have an opening larger than $100 \mathrm{~nm}$. This clearly highlights that size can be a limiting factor for the efficiency of contrast agents.

Hyperosmolar agents like mannitol are often used to temporarily disrupt the BBB and increase its permeability for therapeutic or imaging agents. However, mannitol remains unattractive due to serious side effects such as renal and heart failure, electrolyte disorders, hypovolemia and others. ${ }^{164}$

Polyamines have been reported to increase the permeability of proteins at the BBB. ${ }^{165}$ This could be attributed to the high density capillary network of the brain resulting in a high concentration of negative charges at the $\mathrm{BBB}$, hence an environment selective for positively charged substances like basic peptides or polyamines. ${ }^{166}$ Putrescine is a small organic diamine molecule, which successfully enhanced crossing of the BBB by Gd-DTPA. ${ }^{167}$

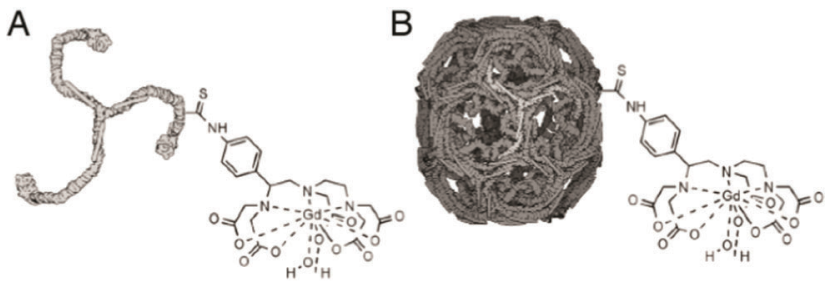

Fig. 5 Representation of clathrin nanoplatforms conjugated to Gd-DTPA. (A) Triskelion; (B) cage. Reprinted from ref. 178. PLOS One, Creative Commons Attribution License.

However, this ability to facilitate the BBB crossing is not universal but strongly depends on the functionalization and nature of the contrast agent. In another study, putrescine was shown to be unable to make SPIONs cross the BBB. ${ }^{168}$ Other polyamines such as pentadiamine or molecules containing amine groups like the amino acids lysine and arginine did not allow the passage of the $\mathrm{BBB}$, even with a hexa-arginine sequence. ${ }^{169,170}$ Recently, a lysine/ arginine sequence was reported to highly increase cell internalization but did not enhance BBB crossing. ${ }^{171}$ In contrast, other peptides ( $\mathrm{PHO}, \mathrm{TGN}$ ) have been reported to facilitate the crossing of the BBB. ${ }^{172,173}$ Similarly, transferrin grafted onto PLGA nanoparticles was shown to improve (20-fold) the crossing of an in vitro model of the BBB through caveola-mediated transcytosis involving a cholesterol-dependent pathway. ${ }^{174}$ In vivo, the same PLGA nanoparticles coated with transferrin targeted the BBB more efficiently compared to BSA-coated NPs. ${ }^{175}$ Similar results were obtained for SPIONs loaded onto mesoporous silica nanoparticles. ${ }^{176}$ Studies with HeLa cells showed that holotransferrin grafted onto SPIONs greatly facilitates cell internalization. ${ }^{177}$ Gd-DTPA complexes conjugated with triskelions $(19 \mathrm{~nm})$ or cages $(55 \mathrm{~nm})$ comprised of clathrin (Fig. 5), a protein involved in cellular internalization, were shown to cross the BBB more efficiently. In addition, the $T 1$ relaxivity of Gd-DTPA associated to clathrin triskelion or cage under a $0.47 \mathrm{~T}$ magnetic field was increased 4 and 20 fold respectively compared to bare Gd-DTPA complexes. ${ }^{178}$ PEG coating was also reported to improve the BBB permeability for $A \beta_{1-42}$-modified USPIONs and to provide good contrast in brain MRI. ${ }^{83}$ However, it was later shown that PEG or poly(ethylene-imine) coatings alone did not enable SPIONs to pass the $\mathrm{BBB}$ without addition of polysorbate $80,{ }^{179}$ an anionic surfactant previously described to favor transport of NPs to the brain. ${ }^{180,181}$ Alkylglyceryl moieties grafted onto chitosan nanoparticles also enhanced the BBB crossing. The permeability of the BBB model used in this study increased with alkyl chain length (butyl, pentyl, and octyl), which was associated with rearrangement at the tight junction level. ${ }^{182}$ Overall, a number of molecules have been shown to facilitate the crossing of the BBB by nanoparticles, although none appears universal and their efficiency should be systematically assessed.

\subsection{Targeting the amyloid plaques}

Amyloid plaques are the natural target of contrast agents for early diagnosis of AD by MRI. As previously mentioned, they are 
Table 1 Examples of the main compounds used to target $A \beta$ aggregates

\begin{tabular}{|c|c|c|}
\hline \multicolumn{2}{|l|}{ Small molecules } & References \\
\hline \multirow{4}{*}{\multicolumn{2}{|c|}{$\begin{array}{l}\text { Curcumin } \\
\text { Pittsburg compound B } \\
\text { DDNP } \\
\text { Sialic acid }\end{array}$}} & 204 and $207-209$ \\
\hline & & 196 and 198 \\
\hline & & $199-203$ \\
\hline & & $210-212$ and 214 \\
\hline \multicolumn{2}{|l|}{ Proteins and peptides } & References \\
\hline \multirow[t]{2}{*}{ Antibodies } & Anti-A $\beta_{1-40}$ & 187 and 188 \\
\hline & Anti-A $\beta P P$ & 82 and 159 \\
\hline \multirow[t]{3}{*}{ Amyloid peptides } & $\mathrm{A} \beta_{1-30}$ & 98 and 168 \\
\hline & $\mathrm{A} \beta_{1-40}$ & 167 and 189 \\
\hline & $\mathrm{A} \beta_{1-42}$ & 83 and 160 \\
\hline \multirow[t]{4}{*}{ Short peptides } & $\mathrm{PHO}$ & 172 \\
\hline & QSH & 173 \\
\hline & LPFFD & 194 \\
\hline & KLVFF & 194 \\
\hline
\end{tabular}

comprised of aggregated amyloid peptides. APP and derived A $\beta$ peptide species are a miscellaneous population. Therefore, the choice of the molecular target (sequence) has a strong impact on the interpretation of the MRI scans and on diagnosis accuracy. In what follows, we present three major kinds of targeting agents designed to specifically bind to amyloid deposits for the MRI of $\mathrm{AD}$, namely antibodies, peptides (amyloid or not) and small molecules (Table 1). Table 2 summarizes actual studies aiming at the monitoring of $\mathrm{A} \beta$ plaques or aggregates, both in vitro and in vivo, involving functionalized chelators or nanoparticles as contrast agents.

3.2.1 Immunotargeting. Sillerud et al. reported SPIONs grafted with anti-A $\beta$ PP antibodies that successfully passed the BBB in the absence of enhancer molecules. ${ }^{159}$ Tested on the transgenic murine model APP/PS1, the functionalized SPIONs were able to bind $A \beta$ plaques and enhanced the MRI detection. Further examination revealed twice as many amyloid deposits using functionalized SPIONs compared to MRI analyses in the absence of contrast agents. ${ }^{159}$ Anti-A $\beta$ PP-conjugated SPIONs were also used in MRI to monitor the reduction in amyloid plaque density after treatment with resveratrol, ${ }^{82}$ an inhibitor of the inflammatory factor $\mathrm{NF}-\mathrm{KB}^{183}$ previously reported to diminish plaque formation. ${ }^{184} \mathrm{HMON}$ contrast agents combining the paramagnetic effect of manganese $\left(\mathrm{Mn}_{3} \mathrm{O}_{4}\right)$ and high specific surface area ${ }^{76,185}$ (Fig. 6A) were successfully decorated with antibodies targeting cancer cells through streptavidin/biotin interactions. ${ }^{186}$ Streptavidin-modified HMON can in fact bind any biotinylated functional molecule and the method was later employed to detect amyloid plaques with an antibody directed against $A \beta_{1-40}$. Anti-A $\beta$-functionalized HMON injected in the cerebrospinal fluid (cisterna magna) of APP/PS1 mice enhanced MRI contrast and allowed for the accurate detection of amyloid deposits, as confirmed by microscopy analysis after staining with thioflavin ${ }^{187,188}$ (Fig. 6B).

3.2.2 Peptides, $\mathbf{A} \boldsymbol{\beta}$ and others. The formation of amyloid plaques originates from the strong propensity of $A \beta$ peptides to spontaneously aggregate. The high affinity of "free" $\mathrm{A} \beta$ peptides $\left(\mathrm{A} \beta_{1-40}\right)$ for existing plaques was successfully exploited for their targeting and in vivo detection by MRI with gadolinium complexes. ${ }^{189}$ However, in this case, the BBB penetration of the contrast agents can only be achieved by coinjection with a solution of mannitol whose side effects prevent their clinical use. ${ }^{164}$ Further functionalization of the same nanoparticles with putrescine proved efficient in crossing the BBB. After injection into the carotid artery of transgenic mice (APP/PS1), such dual-functionalized Gd complexes induced the selective MRI detection of amyloid plaques at $7 \mathrm{~T}$ in ex vivo tissue specimens. ${ }^{167}$ The toxicity of $A \beta_{1-40}$ being a possible issue for in vivo use, recent interest has turned to the $A \beta_{1-30}$ peptide with 6 lysine residues added at the $\mathrm{N}$-terminal. ${ }^{98,168}$ This $\mathrm{K} 6 \mathrm{~A} \beta_{1-30}$ peptide is non-fibrillogenic and non-toxic, while keeping the two major antigenic sites of the longer peptides. ${ }^{190}$ It was successfully combined with Gd complexes to target and detect amyloid plaques by MRI at $7 \mathrm{~T}$ but required the co-injection of mannitol to cross the BBB. ${ }^{168}$

Following a similar strategy, $A \beta_{1-40}$ peptides were adsorbed onto dextran-coated monocrystalline iron-oxide nanoparticles (MION). The $A \beta_{1-40}$-functionalized MIONs exhibited an affinity for $\mathrm{A} \beta_{1-42}$ peptides $\left(K_{\mathrm{D}}=202 \mathrm{nM}\right)$ similar to that of free $\mathrm{A} \beta_{1-40}$ $\left(K_{\mathrm{D}}=266 \mathrm{nM}\right)$. For comparison, the covalent attachment of $\mathrm{A} \beta_{1-40}$ to DTPA used to chelate Gd lowered its affinity for $\mathrm{A} \beta_{1-42}$ peptides by a factor of approximately $2\left(K_{\mathrm{D}}=577 \mathrm{nM}\right) \cdot{ }^{189}$ The intravenous injection of $\mathrm{A} \beta_{1-40}$-functionalized MION in APP/ PS1 mice resulted in the specific targeting of amyloid deposits detected by MRI, while non-functionalized MION did not. Similar enhancement was observed with SPIONs grafted with $\mathrm{A} \beta_{1-42}$ peptides. ${ }^{160}$ Later, Wadghiri et al. reported on the synthesis of ultrasmall SPIONs (USPIONs) functionalized with $\mathrm{A} \beta_{1-42}$ peptides and coated with PEG to spare the mannitol coinjection. ${ }^{83}$ The USPIONs-PEG-A $\beta_{1-42}$ injected intravenously in transgenic mice (APP/PS1), without mannitol co-injection, provided good contrast to image amyloid deposits by $\mu \mathrm{MRI}$.

Other peptides, generally derived from $\mathrm{A} \beta$ peptides, have been used as targeting groups. Heptapeptides PHI (C-FRHMTEQ-C) and PHO (C-IPLPFYN-C), selected by the phage display technique, ${ }^{191}$ exhibit a high affinity for $\mathrm{A} \beta_{1-42}$ peptides. The same group also identified hexapeptides, notably P1 (LIAIMA) and P2 (IFALMG), after screening a phage display library designed from the amino acid sequence of $A \beta_{1-42}$ combined with soft oligonucleotide-directed mutagenesis. ${ }^{172,192}$ The use of such affinity-based techniques ensures the ability of the selected peptides to bind amyloid plaques. SPIONs grafted with PHO peptides were able to cross the $\mathrm{BBB}$ and to spread homogeneously in the brain, leading to contrast enhancement in MRI. It should be noted that the blood retention time of P1-grafted SPIONs is similar to that of PEG-SPIONs $\left(t_{\mathrm{e} 1 / 2}=4.5 \mathrm{~h}\right)$ but appears to be lowered compared to that of SPIONs grafted with the cyclic heptapeptides PHO $\left(t_{\mathrm{e} 1 / 2}=3 \mathrm{~h}\right)$ and PHI $\left(t_{\mathrm{e} 1 / 2}=1.25 \mathrm{~h}\right)$. One week after the injection, the SPIONs were totally eliminated from the body and no in vivo toxicity was observed. ${ }^{172}$ Based on the same phage display strategy, a D-enantiomeric peptide, QSHYRHISPAQV (denoted as QSH), was recently reported to specifically bind $\mathrm{A} \beta_{1-42}$ when conjugated to polymeric nanoparticles. The NPs developed in this work were dually 
Table 2 MRI studies involving imaging and/or monitoring of $A \beta$ aggregates using nanostructures functionalized with compounds enhancing their colloidal stability, furtivity, ability to cross the BBB and/or targeting of the amyloid plaques

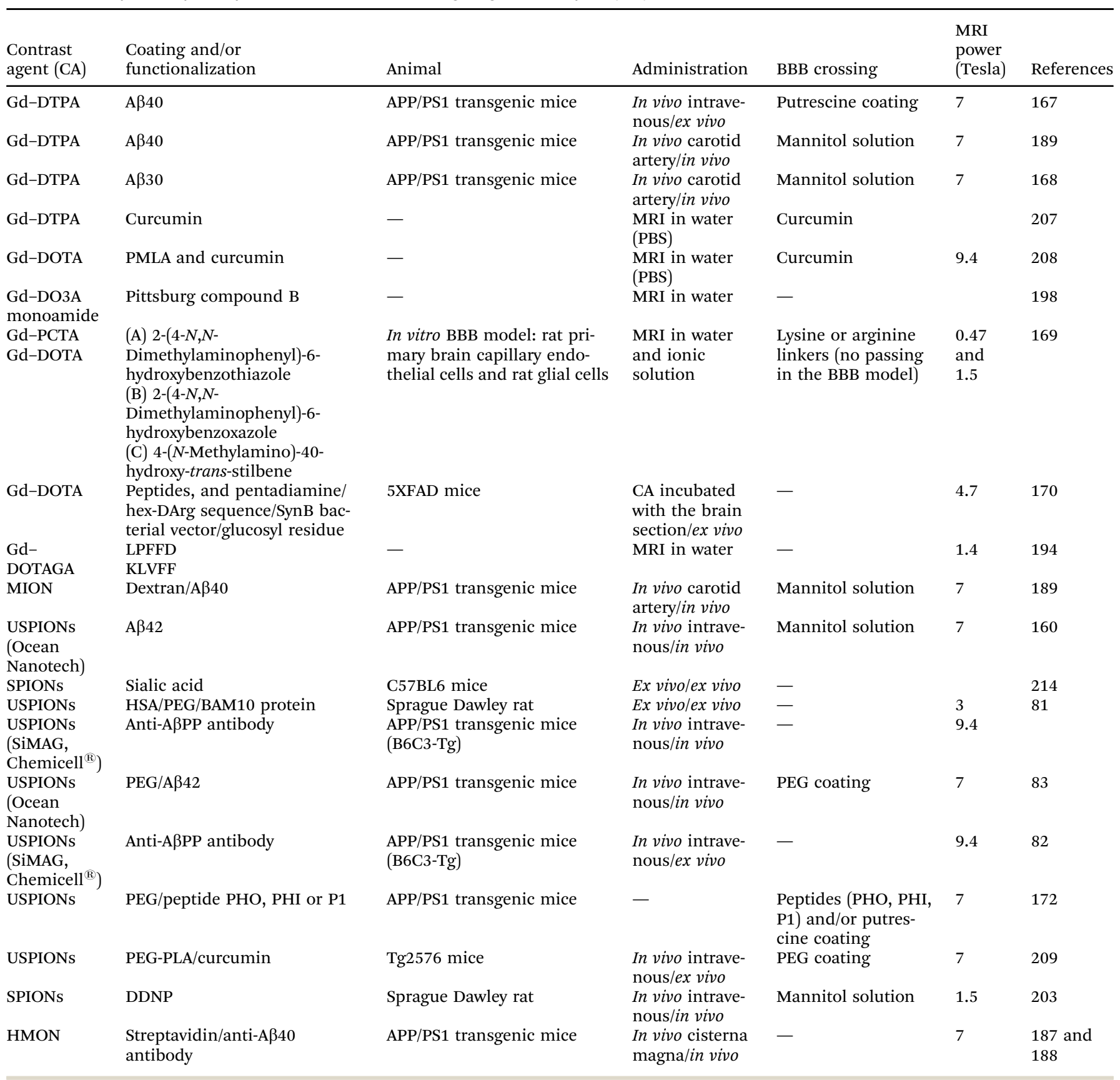

functionalized with another peptide, TGN (TGNYKALHPHNG). The authors demonstrated that these dual-functional nanoparticles were able to efficiently target amyloid plaques in the brains of Alzheimer's disease mice one hour after injection in the tail vein. ${ }^{173}$ Matharu et al. ${ }^{170}$ tested a series of five peptides containing $\beta$-amyloid binding domains and coupled to the gadolinium chelate DOTA. The compound R2 (DOTAGrffvlkrrrrrr$\mathrm{NH} 2$, where lowercase letters denote D-amino acids) exhibited the highest affinity for amyloid species, stronger for fibrils compared to oligomers. All five peptides contained amino acid sequences expected to facilitate crossing of the BBB, like the
hex-DArg sequence (rrrrrr) present at the N-terminus of R2. However, all peptides exhibited poor brain availability. Focused ultrasound with microbubbles was used to enhance the uptake of R2, which was successfully tested for the in vivo MRI detection of amyloid plaques. ${ }^{170}$ Polysiloxane nanoparticles grafted with the gadolinium chelator DOTAGA ${ }^{193}$ were recently used with PEG coating and two peptides derived from $A \beta_{1-42}$ (LPFFD and KLVFF, sequences of $A \beta$ involved in its aggregation) as targeting units to detect $A \beta$ fibrils. ${ }^{194}$ These NPs called AGuIX were able to specifically bind $A \beta$ fibrils $\left(K_{\mathrm{d}}\right.$ of $261 \pm 59 \mu \mathrm{M}$ and $534 \pm 134 \mu \mathrm{M}$ respectively). They provided higher relaxivity than 
A

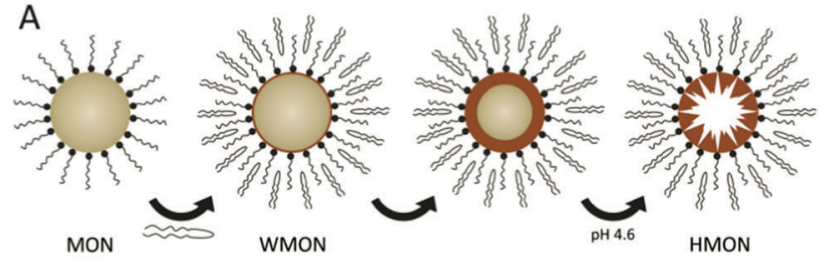

B

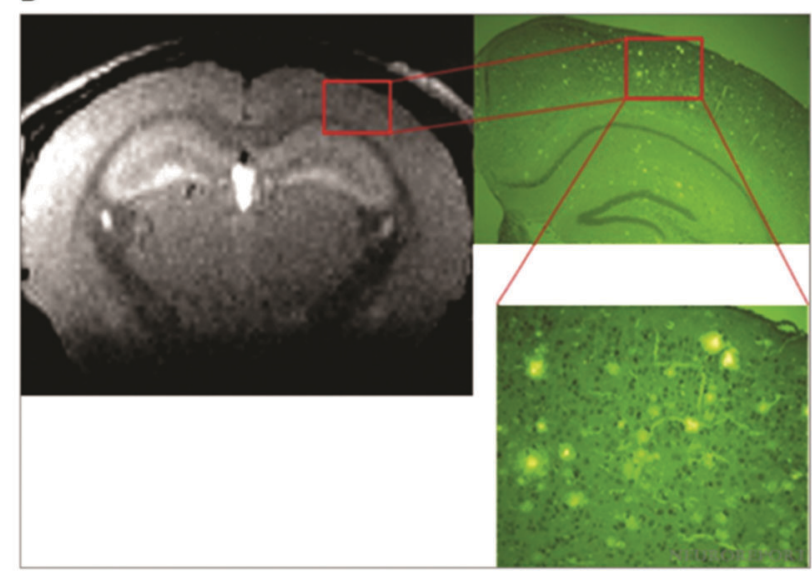

A

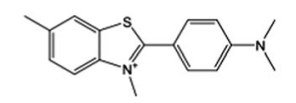

B

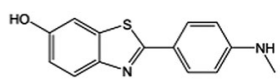

C
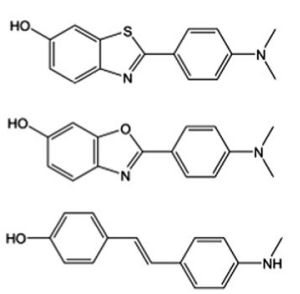

D

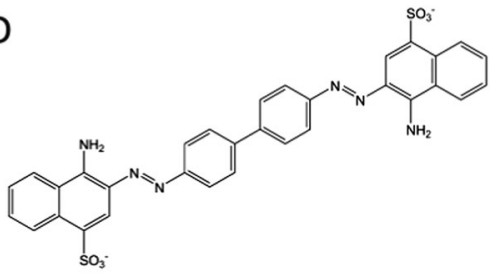

$E$

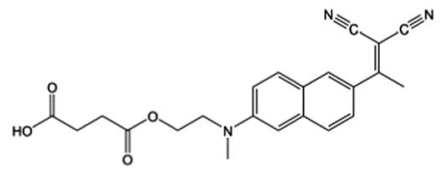

$\mathrm{F}$

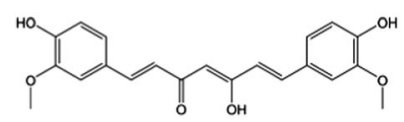

Fig. 7 Representation of some organic molecules able to bind to amyloid fibrils. (A) Thioflavin T. (B) PiB. (C) From top to bottom, molecules derived from PiB: IBOX and stilbene (see ref. 169). (D) Congo Red. (E) DDNP. (F) Curcumin.

Fig. 6 (A) Scheme of $\mathrm{HMON}$ formation. A MnO nanoparticle is initially synthesized, covered by a $\mathrm{Mn}_{3} \mathrm{O}_{4}$ shell, with PEG and oleate adsorbed on the outer surface. The $\mathrm{MnO}$ core is then dissolved $(\mathrm{pH} 4.5)$, producing a hollow $\mathrm{Mn}_{3} \mathrm{O}_{4} \mathrm{NP}$. Clear brown: $\mathrm{MnO}$, brown: $\mathrm{Mn}_{3} \mathrm{O}_{4}$, black-headed ripple: oleate, curved ripple: PEG. Adapted with permission from ref. 185. Copyright (2008) John Wiley and Sons. (B) Detection of amyloid plaques by MRI using HMON functionalized with anti-A $\beta_{1-40}$ antibody ( $T 1$-weighted imaging) and corresponding immunohistochemical thioflavin-S staining on APP/PS1 mice. Reprinted with permission from ref. 187. Copyright (2013) Wolters Kluwer Health.

the commercial contrast agent DOTAREM ${ }^{\circledR}$ (approx. 4-fold higher for both $r 1$ and $r 2$ ) and a comparable $r 2 / r 1$ ratio (1.4 for DOTAREM ${ }^{\mathbb{R}}$, 1.5 with LPFFD peptide, 1.6 with KLVFF).

3.2.3 Small molecules. Some small organic molecules have the ability to bind amyloid deposits. Skeby et al. recently studied the binding mode of many compounds to an amyloid fibril model. Many imaging agents are derived from Congo Red or Thioflavin T (Fig. 7A and D) known to specifically stain amyloid deposits. They both exhibit rigid and aromatic structures, and other compounds with a styryl group or an amino-naphthyl group that share these chemical properties are also able to bind to fibrils (Fig. 7) and have been investigated for MRI. ${ }^{169,195}$ Most imaging agents share a common binding mode on the top or bottom groove of the fibrils (Fig. 8). ${ }^{20}$ Pittsburg compound B (PiB, Fig. $7 \mathrm{~B}$ ) is a Thioflavin $\mathrm{T}$ derivative, whose affinity for amyloid aggregates has been well described. ${ }^{196} \mathrm{PiB}$ is the most studied ligand for detection of amyloid aggregates and is used in clinical trials to diagnose amyloid plaques. ${ }^{197} \mathrm{~A}$ contrast agent based on Gd-DO3A monoamide chelates (1,4,7,10-tetraazacyclododecane-1,4,7-triacetic acid) linked to the PiB moiety was developed and tested by MRI in water and was found to lead to good efficiency thanks to a $T 1$ relaxivity approximately $50 \%$ higher than conventional clinical contrast agents. ${ }^{198}$ DDNP (1,1-dicyano2-[6-(dimethylamino)-naphthalene-2-yl]), a diphenylpropynone

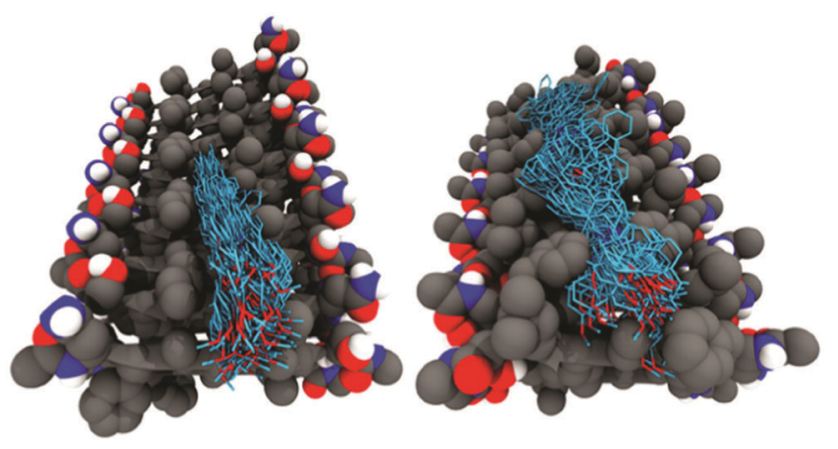

Fig. 8 Visualization of the two principal binding modes (top, bottom) for a molecule from the styryl-based compound group. In gray, structure of amyloid fibrils; in light blue, snapshots of molecular dynamic simulations showing the binding of the molecule. Reprinted with permission from ref. 20. Copyright (2013) American Chemical Society.

derivative, has been reported to exhibit good affinity for amyloid aggregates ${ }^{199,200}$ by binding the $\beta$-sheet domains in amyloid fibrils. ${ }^{201}$ DDNP (Fig. 7E) has been bound to SPIONs by ligand exchange. This contrast agent exhibited high relaxivity by MRI, and showed a high ability to bind to $A \beta_{1-40}$ fibrils in vitro. ${ }^{202}$ The DDNP magnetic nanoparticles have been also tested to detect amyloid plaques by MRI in an $\mathrm{AD}$ rat model after intra-hippocampal injection of $A \beta_{1-40 .}{ }^{203}$ However, the co-injection of mannitol was required to open the BBB.

In a similar approach, the molecules PiB, IBOX (2-(4'dimethylaminophenyl)-6-iodobenzoxazole) and stilbene (Fig. 7C) were derived and coupled to gadolinium complexes (Gd-DOTA, 1,4,7,10-tetraazacyclododecane-1,4,7,10-tetraacetic acid, and Gd-PCTA, 3,6,9,15-tetraaza bicyclo[9.3.1]-pentadeca-1(15),11,13triene-3,6,9-triacetic acid). ${ }^{169}$ The PiB-derived contrast agent showed the best affinity for amyloid deposits. However, attempts at enhancing the BBB-crossing ability of these complexes by introducing lysine or arginine linkers were not successful. 
Curcumin is a non-toxic yellow pigment described to naturally bind amyloid deposits, disrupt amyloid aggregates and cross the BBB. ${ }^{204}$ Like the previously cited compounds, curcumin is a rigid and aromatic molecule with two phenolic cycles (Fig. 7F, enol form). Although some clinical trials suggest a potential benefit of curcumin for the treatment of dementia, ${ }^{205}$ the actual therapeutic efficiency remains questionable. ${ }^{206}$ Nevertheless, the functionalization of Gd-DTPA or Gd-DOTA with curcumin resulted in significant contrast enhancement for the detection of amyloid plaques by MRI in vitro ${ }^{207}$ and ex vivo in mouse and human brain tissues. ${ }^{208}$ In a study by Cheng et al., curcumin was adsorbed onto magnetic nanoparticles (Cur-MNPs) along with PEG, and small resulting aggregates were then stabilized by PEG-PLA and Polyvinylpyrrolidone (PVP) through flash nanoprecipitation. Curcumin molecules were shown to adsorb onto iron oxide through hydrogen bonds, and the nanoparticles (mean particle size under $100 \mathrm{~nm}$ ) tested in transgenic mice were able to cross the BBB. The resulting $T 2$ ex vivo MRI revealed dark spots aligned with amyloid plaques on immunohistochemically stained sections. ${ }^{209}$

Carbohydrate molecules such as sialic acid have also been reported to bind specifically to amyloid peptides. ${ }^{210-212}$ Sialic acid, also called $N$-acetyl neuraminic acid, does not have a rigid structure, in contrast to the previously described molecules. Sialic acid is a monosaccharide found in the ganglioside GM1 present in the cell membrane. GM1 was reported to interact with $\mathrm{A} \beta$, and possibly related to the onset of the disease. ${ }^{213}$ SPIONs were conjugated to sialic acid through their coating with crosslinked and modified dextran. ${ }^{214}$ The magnetic glyconanoparticles were able to specifically bind $\mathrm{A} \beta$ peptides both in vitro and ex vivo in mouse brains. Contrast enhancement was reported in vitro, with a significant decrease in the $T 2$ relaxation time from $23 \mathrm{~ms}$ for sialic acid-coated NPs alone down to $16 \mathrm{~ms}$ in the presence of $\mathrm{A} \beta$. Moreover, the authors demonstrated the potential of these magnetic glyconanoparticles to protect cells from $A \beta$-induced cytotoxicity by sequestering the peptide on the NP surface.

\section{Toxicity of nanomaterials used for brain imaging}

Due to their nanometric size and the associated properties, nano-objects are suspected to induce toxicological reactions. Among the many possible mechanisms, the production of reactive oxygen (ROS) or nitrogen species (RNS) is particularly considered. In fact, many studies report the production of ROS with various materials such as carbon nanotubes, ${ }^{215,216}$ silver NPs,${ }^{217}$ chromium oxide NPs, ${ }^{218}$ silica NPs, ${ }^{219}$ quantum dots ${ }^{220}$ and iron-oxide NPs. ${ }^{221}$ Some materials have redox properties (e.g. iron or manganese) clearly responsible for the production of reactive oxygen. However, nanoparticles devoid of redox properties can also elicit the production of ROS as a cellular response to their presence. ${ }^{220}$ Recently, Lu et al. performed a wide study with particles of different shape, size (from $10 \mathrm{~nm}$ to $18 \mu \mathrm{m})$, origin (ambient air, engineered) and materials $\left(\mathrm{CeCO}_{2}\right.$,
NiO, ZnO for engineered NPs). The main conclusion is that all particles decreased cellular viability as their concentration increased, ${ }^{222}$ often involving the production of ROS. It should be noted that evaluating the impact of nanomaterials on cell viability is a delicate task. In particular, the commonly used MTT assay was reported to produce false positive results when used with some nanomaterials, due their ability to reduce the tetrazolium. ${ }^{223-225}$ Besides, Joris et al. recently investigated the variability in response to NP exposure of the human and murine neuroblastoma cell line, neural progenitor cell line and neural stem cells. ${ }^{226}$ They highlighted cell type- and species-specific behavior concerning ROS, calcium homeostasis, mitochondrial integrity and cell morphology. Table 3 summarizes the conditions and main conclusions of numerous studies on the toxicity of some major nanomaterials among which are gold, iron oxide, manganese and silica NPs. For more detailed insights into the cellular mechanisms involved in nanomaterial toxicity, readers are referred for instance to the review by Sharifi et $a .^{227}$ The main mechanisms responsible for NP toxicity are the generation of oxidative stress, release of free metal ions and the generation of aggregates that cells cannot eliminate. Some authors also reported that NPs can impair the cell cycle and gene expression. ${ }^{228}$

\subsection{General features of NPs influencing their cytotoxicity}

Size. Small $\mathrm{SiO}_{2} \mathrm{NPs}(10 \mathrm{~nm})$ strongly affected the viability of human skin fibroblasts with more than $50 \%$ cell death after 24 hours, whereas larger NPs $(>40 \mathrm{~nm})$ did not disturb cell activity. $^{229}$ This was confirmed by other reports showing that smaller (14 nm) $\mathrm{SiO}_{2}$ NPs are more cytotoxic than larger ones $(>380 \mathrm{~nm}) .{ }^{230}$ In contrast, a toxicological study on gold NPs of 15, 50 and $100 \mathrm{~nm}$ indicated that, although smaller NPs were more readily absorbed by intestinal epithelium cells, they accumulated less. The accumulation of larger NPs in epithelial cells led to depolarization of the mitochondrial membrane, impairing their function and finally resulting in higher cytotoxicity. ${ }^{231}$ The variations in the response of various cell lines are in keeping with the conclusions of a wider study by Kroll et al., who investigated more than 20 nanomaterials with 10 cell types. $^{232}$ Therefore, the effect of size on NP toxicity appears to depend on the materials used as well as the cellular model.

Surface properties. The surface charge exhibited by nanomaterials is an important parameter that can generate cytotoxic effects. Platel et al. showed that PLGA nanoparticles (diameter of approx. $80 \mathrm{~nm})$ with a positive surface charge $(\zeta=+15 \pm 5 \mathrm{mV})$ exhibited much higher cytotoxicity than neutral $(\zeta=-1 \pm 3 \mathrm{mV})$ or negatively charged $(\zeta=-25 \pm 3 \mathrm{mV})$ ones. Endocytosis of positively charged PLGA NPs proved to be higher than that of negatively charged ones and resulted in higher ROS induction and genotoxicity, as assessed by comet and micronucleus assays. $^{219}$

The hydrophobic/hydrophilic balance brought by surface treatment is also involved in toxicological processes. A study of $20 \mathrm{~nm} \mathrm{TiO}_{2}$ NPs showed that both hydrophobic and hydrophilic NPs are able to penetrate buccal epithelial cells after oral administration, in spite of a strong tendency to agglomerate. ${ }^{233}$ 
Table 3 Toxicity studies on nanomaterials used for in vivo MRI

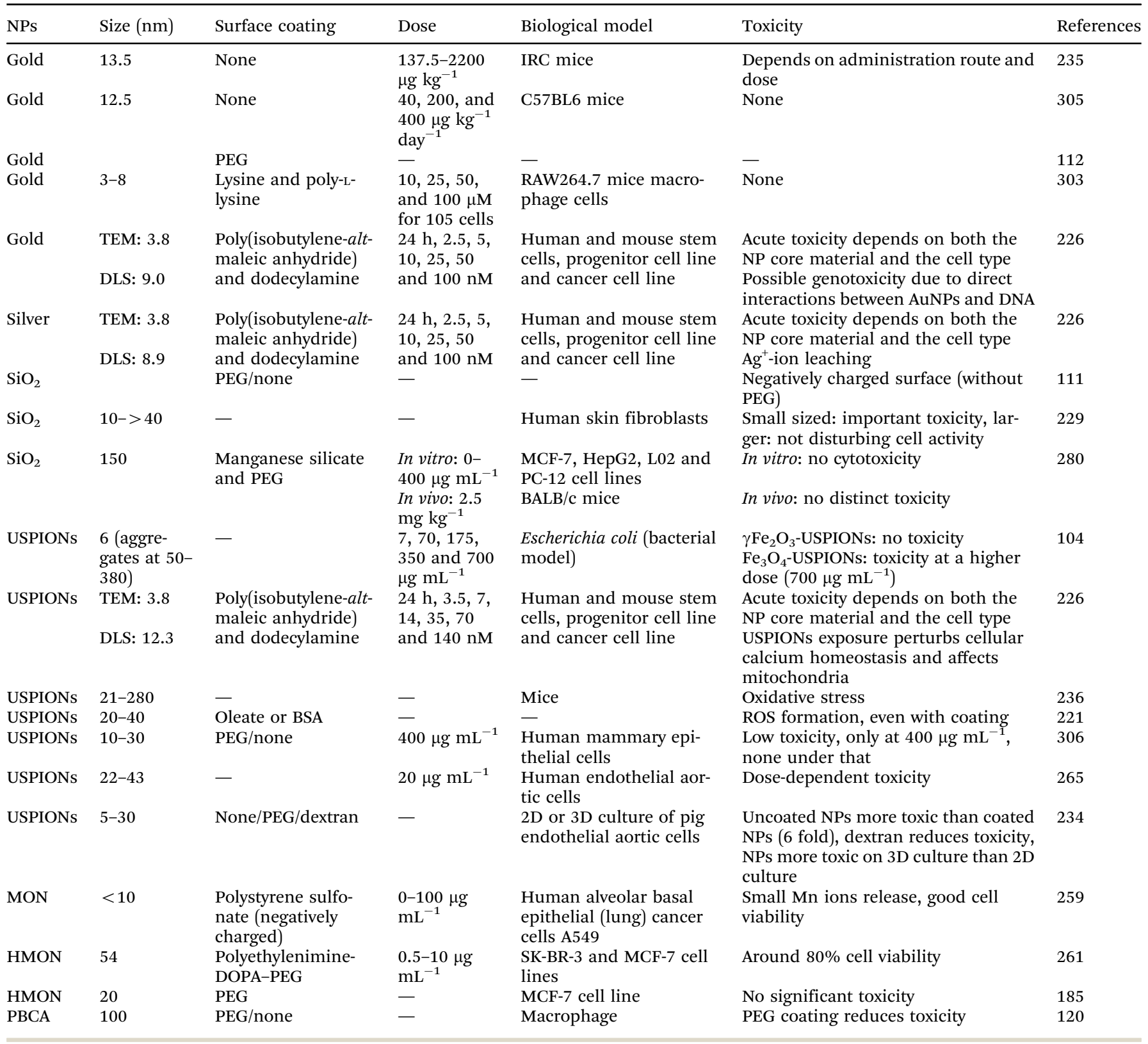

The cell viability was not lowered, but cellular localization differed and hydrophobic NPs were found to have a higher ability to impair the mitochondrial membrane, and thus to generate ROS.

The coating of nanomaterials with polymers like PEG or dextran, besides increasing their stability, was shown to decrease their toxicity. ${ }^{120,121}$ For instance PEG- or dextrancoated iron-oxide nanoparticles (5 $\mathrm{nm}$ and $30 \mathrm{~nm}$ in diameter) had their toxicity decreased by a factor of 6 because of lower ROS formation in cells. ${ }^{234}$

Administration route. The administration route has also been reported to influence the toxicological effects of NPs. ${ }^{235}$ It was demonstrated that the toxicity of gold NPs to ICR mice was higher when administered by an oral route than by intraperitoneal or intravenous (IV) injection. The conclusion of the study is to strongly recommend the intravenous route, although intraperitoneal injection may be a suitable option when IV is not possible. Intranasal administration would also be an attractive way to deliver contrast agents because of the high vascularization of this region. Unfortunately, an in vivo study performed on mice showed a significant oxidative stress in the olfactory bulb and hippocampus after repeated (30 days) intranasal injections of low doses $(130 \mu \mathrm{g}$ per day, i.e. $10 \%$ of the permissible inhalable dose for mouse) of $\mathrm{Fe}_{2} \mathrm{O}_{3}$ SPIONs (average size of 21 and $280 \mathrm{~nm}$ ). ${ }^{236}$

Interactions of nanomaterials with $\mathbf{A} \boldsymbol{\beta}$ peptides. In the context of Alzheimer's disease, it appears obvious that the contrast agent should not induce or favor the formation of new aggregates, 
thus increasing toxicity and aggravating the disease condition. For instance, the effects of different nanoparticles on the fibrillation rate of the protein $\beta 2$-microglobulin were investigated. ${ }^{237}$ It was reported that copolymeric nanoparticles of NiPAM : BAM ( $N$-isopropylacrylamide: $N$-tert-butylacrylamide; 50:50), cerium oxide, hydrophilic polymer-coated quantum dots and multiwalled carbon nanotubes shortened the nucleation lag time and increased the fibrillation rate, suggesting a surface-assisted nucleation process. The authors and others ${ }^{238}$ pointed out that the conditions of this study were far from those of a real biological system where a large number of proteins would compete for adsorption on the surface. Yet, the conclusions of this study and many others raise a specific concern regarding the use of nanoparticles inside the brain for $\mathrm{AD}$ diagnosis if they were to favor the formation of amyloid aggregates. In fact, the same group reported the opposite effect of the same copolymeric nanoparticles on the nucleation rate and fibrillation of $A \beta_{1-40}$ peptides. ${ }^{239}$ The authors attributed the slower aggregation process to the sequestration of $A \beta$ peptides adsorbed onto the NP surface, hence unavailable to participate in fibril formation, thus shifting the fibrillation equilibrium. The differences in the behavior between $A \beta_{1-40}$ peptides and the $\beta 2$-microglobulin protein may arise from different structuration degrees. In any case, the copolymer composition (NiPAM/BAM ratio) also greatly influenced the effect of the nanoparticles on the $A \beta$ fibrillation rate. Increasing proportions of BAM confer a more hydrophobic nature to the nanoparticles as assessed by pyrene fluorescence analysis. Although $\mathrm{A} \beta$ was previously shown to preferentially bind to hydrophobic and positively charged surfaces, the authors demonstrated ${ }^{239}$ that the higher the NiPAM content, the higher the extent of $\mathrm{A} \beta$ binding and fibrillation lag time. They attributed this somewhat counter-intuitive effect to the higher ability of NiPAM units to H-bonding. Therefore, as BAM content is increased, the H-bonding capacity is decreased and the fibrillation inhibitory effect is reduced.

Similarly, four types of inorganic nanoparticles $\left(\mathrm{SiO}_{2}, \mathrm{TiO}_{2}\right.$, $\mathrm{ZrO}_{2}, \mathrm{CeO}_{2}$ ) were tested for their ability to bind $\mathrm{A} \beta_{1-42}$ peptides and accelerate fibril formation. ${ }^{240}$ Only $\mathrm{TiO}_{2}$ NPs effectively decreased the nucleation time, which was attributed by the authors to the higher peptide concentration at the nanoparticle surface. A recent study ${ }^{241}$ suggested a conformational change of the amyloid peptide on the $\mathrm{TiO}_{2} \mathrm{NP}$ surface with a substantial increase in $\beta$-sheet content favoring amyloid fibril formation.

As mentioned earlier (Section 2.2.1), nanoparticles in physiological conditions are coated with a protein corona, whose effects on the $A \beta$ fibrillation process are not fully elucidated. Studies on silica NPs, polystyrene with a carboxyl modified surface, and multi-walled carbon nanotubes showed that the protein corona formed by immersion in $10 \%$ or $100 \%$ plasma inhibited the formation of $A \beta$ fibrils, while the same bare NPs increased the fibrillation rate. ${ }^{242}$ Differential centrifugal sedimentation and TEM observations revealed that the $A \beta$ peptides bind to the nanomaterials' corona surface and nucleate fibrils but further growth into mature fibrils is hampered. ${ }^{242}$ The same group reported that graphene oxide sheets reduced $\mathrm{A} \beta$ fibrillation, an effect enhanced by the presence of a protein corona.
The nucleation lag time of $A \beta_{1-42}$ peptides was shifted from $200 \mathrm{~min}$ without nanomaterials to $400 \mathrm{~min}$ with bare graphene oxide sheets, and to 600 and $900 \mathrm{~min}$ with graphene oxide incubated with respectively $10 \%$ and $100 \%$ fetal bovine serum as the protein source. ${ }^{243}$ Gold NPs (20 and $30 \mathrm{~nm}$ ) and gold nanorods (4 to $20 \mathrm{~nm}$ ) coated with CTAB were reported to inhibit the fibrillation process. The inhibition is thought to proceed through interactions of negatively charged residues with the positively charged surface of the NPs, thus blocking the fibrillation hot spot regions of $\mathrm{A} \beta$ monomers. In contrast, corona-coated gold NPs had less inhibitory effects compared to bare particles, possibly because the adsorbed proteins, from fetal bovine serum or human plasma, impart a slightly positive surface charge to the NPs. ${ }^{244}$

It is interesting to point out that temperature also influences the complex interactions between $\mathrm{A} \beta$ peptides and NP surfaces. In a physiologically relevant range of temperature, silica and polystyrene (PS) NPs exhibited opposite effects. In line with previous works, both hydrophilic silica and hydrophobic PS nanoparticles had an acceleratory effect on amyloid fibrillation. However, while a temperature increase from $37{ }^{\circ} \mathrm{C}$ to $42{ }^{\circ} \mathrm{C}$ resulted in an enhanced acceleratory effect for silica NPs, it had the opposite effect with PS, inducing a strong inhibition of fibril formation. ${ }^{245}$

Obviously, the risks directly associated with the chemical nature of the magnetic core must be considered, given the reported toxicity of the three main metal ions involved in the preparation of the contrasting agents: gadolinium, manganese and iron.

\subsection{Gadolinium}

Gadolinium is a toxic heavy metal of the Lanthanide family. While MRI contrast agents based on Gd-chelates were generally considered safe, they were connected to nephrogenic systemic fibrosis (NSF) disease in 2006. ${ }^{246}$ Although many groups are still working to identify more precisely the behavior of Gd in biological environments, ${ }^{247}$ some recommended to avoid Gd injection in people suffering from kidney failure. ${ }^{248}$ The significant toxicity of chelated Gd contrast agents is due to the release of highly harmful $\mathrm{Gd}^{3+}$ ions when the chelator is degraded. ${ }^{249,250}$ The ionic form $\mathrm{Gd}^{3+}$ has an ionic radius very close to that of the calcium ion $\mathrm{Ca}^{2+}$ (107.8 pm vs $\left.114 \mathrm{pm}\right) . \mathrm{Gd}^{3+}$ can compete with $\mathrm{Ca}^{2+}$ and block calcium-dependent voltage-gated channels ${ }^{251}$ involved in many essential body functions such as muscle contraction (including heart muscle contraction), neurotransmitter release, cell growth and differentiation, neuronal excitability and gene transcription. ${ }^{252,253}$ Nevertheless, despite its known toxic effects, gadolinium is still widely studied for magnetic resonance imaging. ${ }^{254}$

\subsection{Manganese}

Unlike several other transition metals, free manganese was shown to increase LPS-induced nitric oxide production and the amount of inducible nitric oxide (NO) synthase. ${ }^{255}$ Although manganese has a functional role in enzymatic reactions and brain function, its accumulation leads to important toxicity. ${ }^{256-258}$ In particular, 
manganese is suspected to play a role in major neurodegenerative disorders like Alzheimer's disease, Parkinson's disease, Huntington's disease, amyotrophic lateral sclerosis and prion disease. At the molecular and cellular levels, the underlying mechanisms of overexposure to $\mathrm{Mn}$ are the production of reactive oxygen species (ROS), free radicals and toxic metabolites, the alteration of mitochondrial functions, hence of ATP production, and the depletion of cellular antioxidant defense mechanisms. The decreased activity of enzymes involved in ROS protection leads to abnormal neurotransmitter levels (depending on the time of exposure to high levels of $\mathrm{Mn}$ ) and a very large number of brain metabolites appear to be affected. In spite of the toxicity of high levels of manganese ions, several studies have demonstrated the good biocompatibility of manganese oxide nanoparticles. MON coated with polystyrene sulfonate to confer better water dispersibility only released a very small amount of $\mathrm{Mn}$ ions $\left(1.3 \%\right.$ after $48 \mathrm{~h}$ in PBS at $\left.37^{\circ} \mathrm{C}\right)$ and presented good cell viability. ${ }^{259} \mathrm{MON}$ also possess catalytic activity and can partially oxidize organic molecules such as formaldehyde. ${ }^{260}$ Hollow manganese oxide nanoparticles do not seem to be cytotoxic either. ${ }^{185,261}$ NPs comprised of manganese oxide thus appear as a promising alternative to gadolinium chelates as a $T 1$ contrast agent with good biocompatibility. However, due to the potential risk owing to the toxicity of $\mathrm{Mn}$ ions, a size smaller than $10 \mathrm{~nm}$ and appropriate coating are required. ${ }^{262}$

\subsection{Iron}

The main toxicological effect of iron oxide NPs arises from the intracellular generation of ROS. ${ }^{263,264}$ A study by Zhu et al. reported oxidative stress in human endothelial aortic cells (HAEC) and monocytes when incubated with $22 \mathrm{~nm}$ maghemite $\left(\mathrm{Fe}_{2} \mathrm{O}_{3}\right)$ or $43 \mathrm{~nm}$ magnetite $\left(\mathrm{Fe}_{3} \mathrm{O}_{4}\right)$ nanoparticles. ${ }^{265}$ The endothelial cells enter an inflammatory state and drive monocyte adhesion as a consequence of the up-regulation of intracellular cell adhesion molecule-1 (ICAM-1) and interleukin-8 (IL-8) expression, which correspond to early events of atherosclerosis. The authors found the $\mathrm{Fe}_{2} \mathrm{O}_{3}$ NPs to be more toxic than $\mathrm{Fe}_{3} \mathrm{O}_{4}$ NPs, the viability of HAEC being only $30 \%$ after $24 \mathrm{~h}$ exposure to $\mathrm{Fe}_{2} \mathrm{O}_{3}$ NPs at $100 \mu \mathrm{g} \mathrm{mL} \mathrm{mL}^{-1}$ compared to $100 \%$ with $\mathrm{Fe}_{3} \mathrm{O}_{4}$ NPs. After phagocytosis by monocytes (U937), the dissolution due to the acidic $\mathrm{pH}$ of lysosomes was faster for $\mathrm{Fe}_{3} \mathrm{O}_{4^{-}}$ USPIONs than for $\gamma \mathrm{Fe}_{2} \mathrm{O}_{3}$-USPIONs. At the lowest exposure dose tested $\left(0.2 \mu \mathrm{g} \mathrm{mL}^{-1}\right)$ the dissolution was nearly complete after 24 hours. At a higher dose of $20 \mu \mathrm{g} \mathrm{mL} \mathrm{m}^{-1}$, although the concentration of free Fe ions increased slightly, the proportion of dissolved iron did not exceed $1.5 \%$, thus indicating overloading of monocytes machinery. However, a study showed that reactive oxygen species (ROS) formation occurs at the surface of SPIONs independently of their surface chemical nature. For instance, coating of $\gamma \mathrm{Fe}_{2} \mathrm{O}_{3}$-USPIONs $(20-40 \mathrm{~nm})$ with oleate or BSA (Bovine Serum Albumin) did not prevent ROS production. ${ }^{221}$ Wu et al. recently reviewed the mechanisms behind the formation of ROS with iron oxide nanomaterials. ${ }^{266}$ They highlighted that nanoparticles of magnetite $\left(\mathrm{Fe}_{3} \mathrm{O}_{4}\right.$, or $\left.\mathrm{FeO} \cdot \mathrm{Fe}_{2} \mathrm{O}_{3}\right)$ comprising $\mathrm{Fe}(\mathrm{II})$ are also generating more ROS from hydrogen peroxide than maghemite $\left(\mathrm{Fe}_{2} \mathrm{O}_{3}\right) \cdot{ }^{104}$ Despite the ROS production, Auffan et al. reported that $\gamma \mathrm{Fe}_{2} \mathrm{O}_{3}$-USPIONs do not show in vitro toxicity on bacterial wild type Escherichia coli strain, while $\mathrm{Fe}_{3} \mathrm{O}_{4^{-}}$ USPIONs exhibited a limited one. Interestingly, both NPs were significantly more toxic to a double mutant (sodA sodB) E. coli strain deficient in superoxide dismutase activity. According to Auffan $e t$ al., iron oxide toxicity is due to the oxidation of $\mathrm{Fe}(\mathrm{II})$ ions. NPs made of magnetite $\left(\mathrm{Fe}_{3} \mathrm{O}_{4}\right)$ have a surface more sensitive to oxidation and thus lead to higher toxicity: $\gamma \mathrm{Fe}_{2} \mathrm{O}_{3}$ USPIONs which are more stable than $\mathrm{Fe}_{3} \mathrm{O}_{4}$-USPIONs are also less toxic. A recent study on the toxicity of $\mathrm{Fe}_{3} \mathrm{O}_{4}$ nanoparticles reported a decrease in cell viability (NIH3T3 fibroblasts) of approximately $15 \%$ and $25 \%$ after $48 \mathrm{~h}$ of exposure at doses of $32.5 \mathrm{ng} \mathrm{mL}^{-1}$ and $65 \mathrm{ng} \mathrm{mL}^{-1}$ respectively. ${ }^{267}$

Another interaction of iron oxide NPs with cellular components and possible source of toxicity is the induction of structural modifications of proteins adsorbed at the particle surface. More specifically, SPIONs were shown to induce strong conformational changes in transferrin, a protein containing two iron binding sites and physiologically involved in the transport and control of iron level in biological fluids. After incubation with bare or PVAcoated SPIONs, the iron-saturated human transferrin formed a corona around the particles, whose thickness was consistent with the formation of a protein monolayer. Most importantly, the adsorbed transferrin underwent an irreversible conformational change associated with the release of the Fe(III) iron atom, and SPION removal did not allow the recovery of the protein's initial conformation and iron binding capacity. ${ }^{268}$

In this section, we focused on molecular properties of the contrast agents and their impact on cell response and toxicity. Nanomaterials may also induce changes at the higher brain tissue level and immune response as already reviewed elsewhere. ${ }^{269-271} \mathrm{~A}$ recent study compared immune and tissue response following intravenous injection of MR contrast agents gadolinium chelate (Gd-DTPA), iron-oxide NPs (15 nm, with PEG coating) and manganese-oxide NPs (30 nm, with PEG coating) in Balb/c mice. ${ }^{272}$ This work showed iron NPs to be less deleterious to tissues than gadolinium and manganese nanostructures. The levels of pro-inflammatory molecules IL-6 and TNF- $\alpha$ were higher with gadolinium chelate $\left(30 \mu \mathrm{g} \mathrm{g}^{-1}\right.$ $\mathrm{Gd} /$ body) and MON (10 $\mu \mathrm{g} \mathrm{g}^{-1}$ MON/body) compared to control and SPIONs ( $10 \mu \mathrm{g} \mathrm{g}^{-1}$ SPIONs/body), while the total number of white blood cells decreased. Histological analysis showed damage to lungs, kidneys, spleen or liver after exposure to Gd-DTPA/MON. Wu et al. reported that iron NPs accumulate in the striatum after intranasal deposition, which may decrease cell viability by oxidative damage. Yet, at the tissue scale, no visible damage appeared in the striatum after 7 days. ${ }^{273}$ In the past few years, it has been described that injection of gadolinium chelates results in gadolinium deposition in many organs, including the brain, eventually resulting in increased contrast in MR imaging where it accumulates. ${ }^{274}$ However, the FDA recently released a statement that there are no adverse effects due to gadolinium retention in the brain. ${ }^{275}$

To conclude, many parameters appear to play a role in the toxicity of NPs among which are the chemical nature of the core, 
the surface charge, hydrophobicity, nominal size and aggregation state of the particles, the nature and thickness of the coating layer, the possible formation of a protein corona, but also the amount of NPs (dose), the time of incubation and the type of cells in contact with the NPs. ${ }^{276,277}$

\section{The future of MRI for Alzheimer's disease}

Developments of MRI for the early diagnosis of AD will strongly depend on the intrinsic performances of the contrast agents while complying with the highly stringent requirements for future clinical use in humans. A recent review highlighted that core size and composition, as well as the shell or surface coating thickness are the main parameters to consider to enhance the contrast in MRI. ${ }^{278}$ In what follows we review recent advances in the design of contrast agents to enhance their MRI response, as well as ongoing efforts to combine their use for imaging with therapeutic properties following a theranostic approach.

\subsection{Enhancing the contrast agent performances}

A major factor in the efficiency of one particular compound to enhance MRI contrast is its ability to enhance the relaxation of protons from the surrounding water. For this reason, efforts have been made to promote the access of water in close vicinity to the contrast agent. For instance, Kim et al. covered manganese NPs with a layer of mesoporous $\mathrm{SiO}_{2}$, which favors water diffusion towards the manganese core NPs thanks to its high porosity (pore volume of $0.38 \mathrm{~cm}^{3} \mathrm{~g}^{-1}$ ) comprised of straight elongated pores exhibiting an average diameter of $3.3 \mathrm{~nm} .{ }^{279}$ The molar relaxivity $r 1$ measured for the MnO NPs coated with mesoporous silica was $0.65 \mathrm{mM}^{-1} \mathrm{~s}^{-1}$ (11.7 T, $\mathrm{pH} 7.4$ ), much higher than for the same particles coated with PEG $\left(0.11 \mathrm{mM}^{-1} \mathrm{~s}^{-1}\right)$ or dense silica $\left(0.08 \mathrm{mM}^{-1} \mathrm{~s}^{-1}\right)$. Further enhancement can be achieved by using a hollow manganese oxide core, with $r 1=$ $0.99 \mathrm{mM}^{-1} \mathrm{~s}^{-1}$ at $11.7 \mathrm{~T}$ and $1.72 \mathrm{mM}^{-1} \mathrm{~s}^{-1}$ at $1.5 \mathrm{~T}$. For comparison, with similar hollow-manganese oxide particles devoid of silica coating and a magnetic field of $3 \mathrm{~T}$, Shin et al. reported a $r 1$ of $1.42 \mathrm{mM}^{-1} \mathrm{~s}^{-1} \cdot{ }^{185,279}$ Recently, another approach was proposed with a dense $\mathrm{SiO}_{2}$ core, an external layer of mesoporous manganese-silicate and additional outer PEG. The $r 1$ relaxivity in PBS was $0.91 \mathrm{mM}^{-1} \mathrm{~s}^{-1}$ at $3 \mathrm{~T}$ and $\mathrm{pH} 7.4$ and increased in acidic environments up to $4.34 \mathrm{mM}^{-1} \mathrm{~s}^{-1}$ at $\mathrm{pH}$ 5.4. ${ }^{280}$ In spite of these improvements, these relaxivity values at physiological $\mathrm{pH}(\mathrm{pH} 7.4)^{281}$ remain relatively low compared to the commercial Gd-chelate Magnevist ${ }^{\mathbb{R}}$ (Gd-DTPA) which exhibits a $r 1$ of 3.3/4.1/4.3 $\mathrm{mM}^{-1} \mathrm{~s}^{-1}$ (in water/plasma/blood) at $1.5 \mathrm{~T}$, $3.1 / 3.7 / 3.8 \mathrm{mM}^{-1} \mathrm{~s}^{-1}$ (in water/plasma/blood) at $3 \mathrm{~T}$ and $3.1 \mathrm{mM}^{-1} \mathrm{~s}^{-1}$ (in blood) at $7 \mathrm{~T} .^{282,283}$

Another major improvement for accurate diagnosis would be brought about by a functional dual $T 1 / T 2$-weighted contrast agent. The possibility to compare both weighed images would allow for a strong accuracy gain and safer diagnosis by limiting ambiguities. $^{284}$ For instance, a recently reported structure combines a manganese-iron oxide $T 2$-responding core with a gadolinium oxide T1-responding outer layer. A silica separation layer prevents the magnetic field generated by the core from quenching the $T 1$ signal generated by the external layer. Under a field of $3 \mathrm{~T}$, the relaxivity $r 1$ could be modulated from 2.0 to $32.5 \mathrm{mM}^{-1} \mathrm{~s}^{-1}$ by adjusting the thickness of the silicate layer between 4 and $20 \mathrm{~nm}$. This compares well with Magnevist ${ }^{\mathbb{R}}$ relaxivity $r 1$ of approx. $3 \mathrm{mM}^{-1} \mathrm{~s}^{-1}$ at $3 \mathrm{~T}$. Relaxivity $r 2$ is reported to be at least two times higher (from 332 to $216 \mathrm{mM}^{-1} \mathrm{~s}^{-1}$ ) than that of Feridex ${ }^{\circledR}\left(108 \mathrm{mM}^{-1} \mathrm{~s}^{-1}\right) \cdot{ }^{285}$ Other similar NPs with a $\mathrm{Fe}_{3} \mathrm{O}_{4}$ core, a $\mathrm{SiO}_{2}$ separation layer and an outer $\mathrm{Gd}_{2} \mathrm{O}\left(\mathrm{CO}_{3}\right)_{2}$ shell exhibited limited toxicity on the human hepatic cell line HL-7702 and human hepato-carcinoma cell lines Bel-7404 and SMMC-7721. ${ }^{286}$ By adjusting the thickness of the $\mathrm{SiO}_{2}$ separation layer between 8 and $20 \mathrm{~nm}$, the authors reported in a field of $3 \mathrm{~T}$, an $r 1$ relaxivity ranging between 3.7 and $32.2 \mathrm{mM}^{-1} \mathrm{~s}^{-1}$ and $r 2$ between 312 and $208 \mathrm{mM}^{-1} \mathrm{~s}^{-1}$. Cheng et al. constructed a dumbbell-shaped hetero-nanotrimer which exhibits both $T 1$ and $T 2$ signal enhancement. ${ }^{287}$ The particles have an average size of $20 \mathrm{~nm}$ (DLS, TEM), with a platinum cube connecting two spherical nanocrystals of respectively iron oxide and gold. The iron-oxide moiety was made biocompatible by PEGylation. The gold surface was covered by DOTA chelators to stabilize its surface and then conjugated with $\mathrm{Gd}^{3+}$ ions for $T 1$-weighted imaging. The authors reported an approximately two-fold increase in $T 1$ efficiency when either increasing the length of the titanium spacer because of changes in the magnetic coupling effect or increasing the size of the gold particle. Manganese-oxide nanoparticles were recently developed with a time-dependent $T 2 / T 1$ switch upon dissolution. ${ }^{288}$ At short times, NPs act as $T 2$ contrast agents and, as dissolution proceeds, the released $\mathrm{Mn}^{2+}$ ions behave as $T 1$ contrast agents. This system was tested in pig and rat eyes and allowed for efficient dual T1/T2 MRI. Nevertheless, this kind of T2/T1 switch remains dependent on the NP dissolution rate and may raise concerns regarding the possible toxicity of accumulating $\mathrm{Mn}^{2+}$ ions.

\subsection{Beyond diagnosis, towards theranostics of $\mathrm{AD}$}

Accurate detection of amyloid plaques at early stages of formation with a high spatial resolution certainly is of great interest to study the biological mechanisms underlying Alzheimer's disease. It is also a valuable tool to evaluate the efficiency of therapeutic agents, as reported with the drug resveratrol. ${ }^{82}$ In contrast, the application of MRI to systematic early diagnosis of $\mathrm{AD}$ remains questionable, principally for economic reasons and limited access to MRI facilities. Laske $e t$ al. calculated that with about 11000 MRI devices operating in the USA and considering only the population aged 65 and above, each MRI machine should be used to diagnose 3636 people per year, up to above 6000 in $2030 .{ }^{289}$ It is therefore unlikely that MRI would become a routine tool for $\mathrm{AD}$ early diagnosis with the current state of development of the technology.

However, the combination of therapeutic functionalities with the diagnosis abilities of MRI contrast agents ${ }^{290}$ following a theranostic strategy could bring an interesting perspective to Alzheimer's disease diagnosis and therapeutics. ${ }^{291}$ Theranostics in general is the object of growing interest for a wide range of 


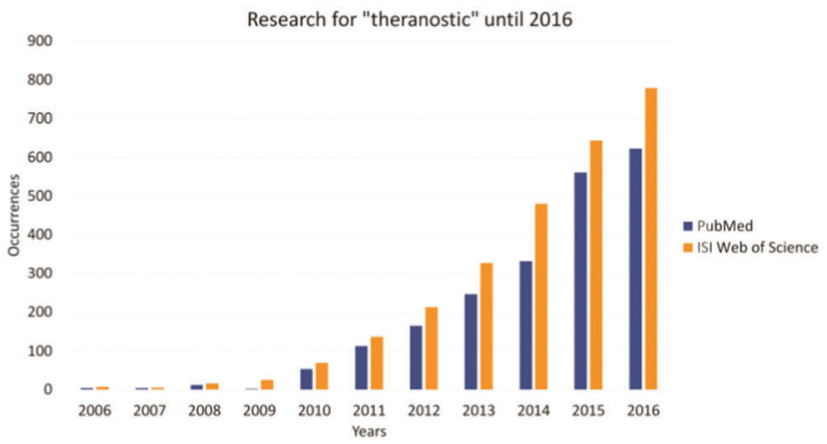

Fig. 9 Increasing interest in theranostics illustrated by the growing number of publications as estimated from PubMed and ISI Web of Science databases.

medical indications as attested by the rapid increase in article number (Fig. 9), well above the global 5.7\% annual growth rate of scientific publication. ${ }^{292}$ In the more specific framework of $\mathrm{AD}$ theranostics, nanoparticles are persistently investigated ${ }^{293-295}$ in spite of the current lack of drugs exhibiting a clear therapeutic effect. In fact, the development of new drugs for AD has often been confronted with failure at the clinical stage, although there are still several clinical studies currently running. ${ }^{8}$ Among the many therapeutic options, one can cite for instance immunotherapybased treatments for $A \beta$ removal $^{8}$ and hampering $A \beta$ fibril formation (see Section 4.1 and ref. 242-244).

Besides, recent achievements in the development of MRI theranostic agents for other indications could easily be adapted for AD. Some good results were obtained with a theranostic agent designed for cerebral amyloid angiopathy (CAA). Chitosan nanoparticles were grafted with a gadolinium DTPA chelate (Magnevist ${ }^{\mathbb{R}}$ ) and an antibody fragment to target amyloid deposits, and then loaded with cyclophosphamide (CYC). CYC is an immunosuppressant drug, which exhibits serious sideeffects when administered in the long term. The association of CYC and targeted contrast agents allowed for early detection and presymptomatic treatment of CAA. ${ }^{127}$ In most theranostic agents based on nanoparticles, the drug is loaded into the polymeric coating layer, which, as already discussed earlier in this review, can be typically formed with PEG or polysaccharides like chitosan, dextran or hyaluronic acid. ${ }^{138}$ Aliphatic polymers are also reported to offer good performances in theranostic applications when coupled to contrast agents like SPIONs or gadolinium. Their well-known and developed chemistry, their proved biocompatibility and degradability, and their ability to be loaded with drugs make them ideal candidates for theranostics. ${ }^{137}$ Gold, ${ }^{296}$ gadolinium ${ }^{254}$ or iron oxide nanoparticles, ${ }^{297,298}$ possibly doped with manganese and zinc, ${ }^{299}$ are also considered for theranostics. Nandwana et al. developed metal-doped SPIONs with an $8 \mathrm{~nm}$ magnetic core and a nitrodopamine-PEG coating to enhance their biocompatibility. These NPs were useful for MRI diagnosis and could be used as theranostic agents in the context of cancer as they can be thermally activated. ${ }^{299}$ In the same context of cancer treatment, another study by Jia et al. showed iron oxide NPs to be useful in theranostics when grafted with the anticancer drug doxorubicin. ${ }^{300}$ The authors additionally adsorbed a plasmid encoding pro-apoptotic protein p53 onto the NP surface and complexed it with a custom-made polycation. Their multifunctional particles still exhibited MRI response, while being able to release the drug and to efficiently induce the expression of the protein. They reported a strong anti-proliferative effect ascribed to the combination of gene therapy and chemotherapy.

Because oxidative stress is clearly implicated in neuronal damage and the progression of $\mathrm{AD}$ (see Section 1), limiting the concentration of ROS to prevent their deleterious effects is one therapeutic approach currently investigated. For instance, adsorbed caffeic acid was recently shown to noticeably limit ROS effects in human brain cancer cells after 24 hours exposure to $\gamma \mathrm{Fe}_{2} \mathrm{O}_{3}$ SPIONs. ${ }^{301}$ Cerium oxide $\left(\mathrm{CeO}_{2}\right)$ NPs conjugated with triphenylphosphonium (TPP) were recently shown to efficiently scavenge ROS and to suppress neuronal death in $5 \mathrm{XFAD}$ mice. ${ }^{302}$ This effect was attributed to the positive surface charge of the TPP coating targeting mitochondria, which are largely involved in the intracellular generation of ROS, and the ROS-scavenging activity of ceria. Similarly, materials made of other inorganic species like gold exhibited antioxidant effects ${ }^{303}$ and could be used for instance as active coating of contrast agents. Alternatively, excess ROS production can be exploited to activate ROS-nanomaterials, such as selenium- or polyoxalate-based nanoparticles, either by directly preventing ROS-induced oxidation or by the triggered release of drugs. ${ }^{304}$

\section{Conclusions}

In this article, we have provided a comprehensive review of the latest achievements in the design of nanoparticles as contrast agents for the MRI of Alzheimer's disease and presented several opportunities for future developments. Acquiring data on the emergence and spreading of amyloid plaques in MRI requires highly efficient non-toxic contrast agents. It appears clearly that, in spite of already available commercial products, some specifically designed nanoparticles are a valuable alternative to current contrast agents for brain MRI and in particular $\mathrm{AD}$ diagnosis. Toxicity of NPs, certainly one primary and major concern, can be reduced by changing the composition of the metal core, preventing NP aggregation through stabilizing surface coating or by limiting the oxidative stress generated by ROS production.

Most importantly, the ability of MRI to help establish an accurate diagnosis largely relies on the efficiency of the contrast agents to image the senile plaques with a strong and specific contrast. This major issue can be addressed in several ways, namely by increasing the relaxivity of the contrast agents, by promoting the crossing of the blood-brain-barrier and by efficiently targeting the amyloid deposits. For instance, we have seen that coating with mesoporous silica favors the interaction of water with the contrast agent, hence providing better relaxivity. Another option would be to design functional dual T1/T2-weighted contrast agents. Grafting of polymers onto the NP surface has a beneficial effect on the blood circulation time and crossing of the BBB. Polyamines and some peptides have also been shown 
to impart NPs a higher ability to cross the barrier, although none of these solutions appear universal and their efficiency should be systematically assessed. As for specifically labeling the senile plaques, efficient targeting has been reported with anti-A $\beta$ antibodies, short peptides and small molecules exhibiting a high affinity for the amyloid structures.

The future of MRI for the diagnosis of $\mathrm{AD}$ is strongly dependent on economic considerations. Although it is unlikely that MRI will become a routine tool for early diagnosis in the short term, the combination of contrast agent NPs with therapeutic functionalities could provide innovative solutions for the overall management of $\mathrm{AD}$.

\section{Conflicts of interest}

There are no conflicts of interest to declare.

\section{References}

1 D. E. Barnes and K. Yaffe, Lancet Neurol., 2011, 10, 819-828.

2 R. Brookmeyer, E. Johnson, K. Ziegler-Graham and H. M. Arrighi, Alzheimer's Dementia, 2007, 3, 186-191.

3 M. Prince, A. Wimo, M. Guerchet, G. C. Ali, Y.-T. Wu and M. Prina, Alzheimer's Dis. Int., 2015, 84.

4 K. M. Langa, Alzheimer's Res. Ther., 2015, 7, 34.

5 B. Winblad, P. Amouyel, S. Andrieu, C. Ballard, C. Brayne, H. Brodaty, A. Cedazo-Minguez, B. Dubois, D. Edvardsson, H. Feldman, L. Fratiglioni, G. B. Frisoni, S. Gauthier, J. Georges, C. Graff, K. Iqbal, F. Jessen, G. Johansson, L. Jönsson, M. Kivipelto, M. Knapp, F. Mangialasche, R. Melis, A. Nordberg, M. O. Rikkert, C. Qiu, T. P. Sakmar, P. Scheltens, L. S. Schneider, R. Sperling, L. O. Tjernberg, G. Waldemar, A. Wimo and H. Zetterberg, Lancet Neurol., 2016, 15, 455-532.

6 A. Wimo, L. Jönsson, J. Bond, M. Prince and B. Winblad, Alzheimer's Dementia, 2013, 9, 1-11.

7 P. A. Adlard and B. J. Cummings, Neurobiol. Aging, 2004, 25, 725-733.

8 R. Anand, K. D. Gill and A. A. Mahdi, Neuropharmacology, 2014, 76(Part A), 27-50.

9 M. Kivipelto, E.-L. Helkala, M. P. Laakso, T. Hänninen, M. Hallikainen, K. Alhainen, H. Soininen, J. Tuomilehto and A. Nissinen, BMJ, 2001, 322, 1447-1451.

10 P. S. Hauser and R. O. Ryan, Curr. Alzheimer Res., 2013, 10, 809-817.

11 E. S. Musiek and D. M. Holtzman, Nat. Neurosci., 2015, 800-806.

12 S. Musardo, C. Saraceno, S. Pelucchi and E. Marcello, Eur. J. Pharmacol., 2013, 719, 84-106.

13 D. P. Perl, Neurol. Clin., 2000, 18, 847-864.

14 K. Wisniewski, G. A. Jervis, R. C. Moretz and H. M. Wisniewski, Ann. Neurol., 1979, 5, 288-294.

15 J. A. Hardy and G. A. Higgins, Science, 1992, 256, 184-185. 16 J. Hardy and D. J. Selkoe, Science, 2002, 297, 353-356.
17 G. G. Glenner and C. W. Wong, Biochem. Biophys. Res. Commun., 1984, 120, 885-890.

18 C. Reinhard, S. S. Hébert and B. De Strooper, EMBO J., 2005, 24, 3996-4006.

19 H. Zhang, Q. Ma, Y. Zhang and H. Xu, J. Neurochem., 2012, 120, 9-21.

20 K. K. Skeby, J. Sørensen and B. Schiøtt, J. Am. Chem. Soc., 2013, 135, 15114-15128.

21 A. I. Plácido, C. M. F. Pereira, A. I. Duarte, E. Candeias, S. C. Correia, R. X. Santos, C. Carvalho, S. Cardoso, C. R. Oliveira and P. I. Moreira, BBA, Biochim. Biophys. Acta, Mol. Basis Dis., 2014, 1842, 1444-1453.

22 S. Jiang, Y. Li, X. Zhang, G. Bu, H. Xu and Y. Zhang, Mol. Neurodegener., 2014, 9, 6.

23 T. E. Golde, S. Estus, M. Usiak, L. H. Younkin and S. G. Younkin, Neuron, 1990, 4, 253-267.

24 J. Kang and B. Müller-Hill, Biochem. Biophys. Res. Commun., 1990, 166, 1192-1200.

25 J. Löffler and G. Huber, J. Neurochem., 1992, 59, 1316-1324.

26 R. L. Neve, E. A. Finch and L. R. Dawes, Neuron, 1988, 1, 669-677.

27 H. A. Rohan de Silva, A. Jen, C. Wickenden, L. S. Jen, S. L. Wilkinson and A. J. Patel, Brain Res. Mol. Brain Res., 1997, 47, 147-156.

28 M. G. Spillantini, S. P. Hunt, J. Ulrich and M. Goedert, Brain Res. Mol. Brain Res., 1989, 6, 143-150.

29 D. Burdick, B. Soreghan, M. Kwon, J. Kosmoski, M. Knauer, A. Henschen, J. Yates, C. Cotman and C. Glabe, J. Biol. Chem., 1992, 267, 546-554.

30 J. Näslund, A. Schierhorn, U. Hellman, L. Lannfelt, A. D. Roses, L. O. Tjernberg, J. Silberring, S. E. Gandy, B. Winblad and P. Greengard, Proc. Natl. Acad. Sci. U. S. A., 1994, 91, 8378-8382.

31 X. Sun, W.-D. Chen and Y.-D. Wang, Front. Pharmacol., 2015, 6, 221.

32 S. A. Gravina, L. Ho, C. B. Eckman, K. E. Long, L. Otvos, L. H. Younkin, N. Suzuki and S. G. Younkin, J. Biol. Chem., 1995, 270, 7013-7016.

33 H. Mori, K. Takio, M. Ogawara and D. J. Selkoe, J. Biol. Chem., 1992, 267, 17082-17086.

34 I. Allaman, M. Gavillet, M. Bélanger, T. Laroche, D. Viertl, H. A. Lashuel and P. J. Magistretti, J. Neurosci., 2010, 30, 3326-3338.

35 P. H. Axelsen, H. Komatsu and I. V. J. Murray, Physiology, 2011, 26, 54-69.

36 K. Zou, J.-S. Gong, K. Yanagisawa and M. Michikawa, J. Neurosci., 2002, 22, 4833-4841.

37 A. Monji, H. Utsumi, T. Ueda, T. Imoto, I. Yoshida, S. Hashioka, K. Tashiro and N. Tashiro, J. Neurochem., 2001, 77, 1425-1432.

38 H. Kadowaki, H. Nishitoh, F. Urano, C. Sadamitsu, A. Matsuzawa, K. Takeda, H. Masutani, J. Yodoi, Y. Urano, T. Nagano and H. Ichijo, Cell Death Differ., 2005, 12, 19-24.

39 M.-N. Labour, S. Vigier, D. Lerner, A. Marcilhac and E. Belamie, Acta Biomater., 2016, 37, 38-49. 
40 J. Godyń, J. Jończyk, D. Panek and B. Malawska, Pharmacol. Rep., 2016, 68, 127-138.

41 M. W. Weiner, D. P. Veitch, P. S. Aisen, L. A. Beckett, N. J. Cairns, R. C. Green, D. Harvey, C. R. Jack, W. Jagust, E. Liu, J. C. Morris, R. C. Petersen, A. J. Saykin, M. E. Schmidt, L. Shaw, J. A. Siuciak, H. Soares, A. W. Toga and J. Q. Trojanowski, Alzheimers Dement. J. Alzheimers Assoc., 2012, 8, S1-S68.

42 M. W. Weiner and D. P. Veitch, Alzheimer's Dementia, 2015, 11, 730-733.

43 T. Yang, T. T. O’Malley, D. Kanmert, J. Jerecic, L. R. Zieske, H. Zetterberg, B. T. Hyman, D. M. Walsh and D. J. Selkoe, Alzheimer's Res. Ther., 2015, 7, 14.

44 C.-C. Yang, S.-Y. Yang, J.-J. Chieh, H.-E. Horng, C.-Y. Hong, H.-C. Yang, K. H. Chen, B. Y. Shih, T.-F. Chen and M.-J. Chiu, ACS Chem. Neurosci., 2011, 2, 500-505.

45 W. J. Jagust, S. M. Landau, R. A. Koeppe, E. M. Reiman, K. Chen, C. A. Mathis, J. C. Price, N. L. Foster and A. Y. Wang, Alzheimer's Dementia, 2015, 11, 757-771.

46 K. A. Johnson, N. C. Fox, R. A. Sperling and W. E. Klunk, Cold Spring Harbor Perspect. Med., 2012, 2, a006213.

47 J. G. Dubroff and I. M. Nasrallah, Acad. Radiol., 2015, 22, 988-994.

48 A. G. Zippo and I. Castiglioni, Curr. Alzheimer Res., 2016, 13, 487-497.

49 J. F. Schenck, J. Magn. Reson. Imaging, 2000, 12, 2-19.

50 Vijayalaxmi, M. Fatahi and O. Speck, Mutat. Res., 2015, 764, 51-63.

51 D. Bendahan, G. Kozak-Ribbens, L. Rodet, S. ConfortGouny and P. J. Cozzone, Anesthesiology, 1998, 88, 96-107.

52 T. Ohkawa, US6521210 B2, 2003.

53 R. Reddy, E. K. Insko, E. A. Noyszewski, R. Dandora, J. B. Kneeland and J. S. Leigh, Magn. Reson. Med., 1998, 39, 697-701.

54 H. Benveniste, G. Einstein, K. R. Kim, C. Hulette and G. A. Johnson, Proc. Natl. Acad. Sci. U. S. A., 1999, 96, 14079-14084.

55 J. Zhang, P. Yarowsky, M. N. Gordon, G. Di Carlo, S. Munireddy, P. C. M. van Zijl and S. Mori, Magn. Reson. Med., 2004, 51, 452-457.

56 J. A. Helpern, S.-P. Lee, M. F. Falangola, V. V. Dyakin, A. Bogart, B. Ardekani, K. Duff, C. Branch, T. Wisniewski, M. J. de Leon, O. Wolf, J. O'Shea and R. A. Nixon, Magn. Reson. Med., 2004, 51, 794-798.

57 C. R. Jack, M. Garwood, T. M. Wengenack, B. Borowski, G. L. Curran, J. Lin, G. Adriany, O. H. J. Gröhn, R. Grimm and J. F. Poduslo, Magn. Reson. Med., 2004, 52, 1263-1271.

58 T. M. Wengenack, S. Whelan, G. L. Curran, K. E. Duff and J. F. Poduslo, Neuroscience, 2000, 101, 939-944.

59 R. A. Armstrong, Folia Neuropathol., 2007, 45, 108-114.

60 FDA, Drug Safety and Availability - FDA Drug Safety Communication, http://www.fda.gov/Drugs/DrugSafety/ucm455386. htm, accessed February 3, 2017.

61 V. C. Pierre, M. J. Allen and P. Caravan, JBIC, J. Biol. Inorg. Chem., 2014, 19, 127-131.
62 P. Caravan, J. J. Ellison, T. J. McMurry and R. B. Lauffer, Chem. Rev., 1999, 99, 2293-2352.

63 P. Caravan, Chem. Soc. Rev., 2006, 35, 512-523.

64 B. M. Dale, M. A. Brown and R. C. Semelka, MRI Basic Principles and Applications, John Wiley \& Sons, Ltd, 2015, pp. 189-195.

65 C. Burtea, S. Laurent, L. V. Elst and R. N. Muller, Molecular Imaging I, Springer, Berlin, Heidelberg, 2008, pp. 135-165.

66 V. M. Runge, J. A. Clanton, W. A. Herzer, S. J. Gibbs, A. C. Price, C. L. Partain and A. E. James, Radiology, 1984, 153, 171-176.

67 R. B. Lauffer, Chem. Rev., 1987, 87, 901-927.

68 A. Petiet, M. Santin, A. Bertrand, C. J. Wiggins, F. Petit, D. Houitte, P. Hantraye, J. Benavides, T. Debeir, T. Rooney and M. Dhenain, Neurobiol. Aging, 2012, 33, 1533-1544.

69 S. Kumar, V. K. Meena, P. P. Hazari and R. K. Sharma, Int. J. Pharm., 2016, 506, 242-252.

70 G. Pelled, H. Bergman, T. Ben-Hur and G. Goelman, J. Magn. Reson. Imaging, 2007, 26, 863-870.

71 T. Watanabe, J. Radulovic, J. Spiess, O. Natt, S. Boretius, J. Frahm and T. Michaelis, NeuroImage, 2004, 22, 860-867.

72 X. Yu, Y. Z. Wadghiri, D. H. Sanes and D. H. Turnbull, Nat. Neurosci., 2005, 8, 961-968.

73 B. Gallez, G. Bacic and H. M. Swartz, Magn. Reson. Med., 1996, 35, 14-19.

74 E. M. Gale, I. P. Atanasova, F. Blasi, I. Ay and P. Caravan, J. Am. Chem. Soc., 2015, 137, 15548-15557.

75 H. B. Na, J. H. Lee, K. An, Y. I. Park, M. Park, I. S. Lee, D.-H. Nam, S. T. Kim, S.-H. Kim, S.-W. Kim, K.-H. Lim, K.-S. Kim, S.-O. Kim and T. Hyeon, Angew. Chem., Int. Ed., 2007, 46, 5397-5401.

76 K. An, S. G. Kwon, M. Park, H. B. Na, S.-I. Baik, J. H. Yu, D. Kim, J. S. Son, Y. W. Kim, I. C. Song, W. K. Moon, H. M. Park and T. Hyeon, Nano Lett., 2008, 8, 4252-4258.

77 Z. Zhen and J. Xie, Theranostics, 2012, 2, 45-54.

78 M. A. Busquets, R. Sabate and J. Estelrich, Nanoscale Res. Lett., 2014, 9, 538.

79 E. Tombácz, R. Turcu, V. Socoliuc and L. Vékás, Biochem. Biophys. Res. Commun., 2015, 468, 442-453.

80 D. Pouliquen, R. Perdrisot, A. Ermias, S. Akoka, P. Jallet and J. J. Le Jeune, Magn. Reson. Imaging, 1989, 7, 619-627.

81 H. Skaat, E. Corem-Slakmon, I. Grinberg, D. Last, D. Goez, Y. Mardor and S. Margel, Int. J. Nanomed., 2013, 8, 4063-4076.

82 N. O. Solberg, R. Chamberlin, J. R. Vigil, L. M. Deck, J. E. Heidrich, D. C. Brown, C. I. Brady, T. A. Vander Jagt, M. Garwood, M. Bisoffi, V. Severns, D. L. Vander Jagt and L. O. Sillerud, J. Alzheimers Dis., 2014, 40, 191-212.

83 Y. Z. Wadghiri, J. Li, J. Wang, D. M. Hoang, Y. Sun, H. Xu, W. Tsui, Y. Li, A. Boutajangout, A. Wang, M. de Leon and T. Wisniewski, PLoS One, 2013, 8, e57097.

84 J. L. Kirschvink, A. Kobayashi-Kirschvink and B. J. Woodford, Proc. Natl. Acad. Sci. U. S. A., 1992, 89, 7683-7687.

85 J. Dobson, Exp. Brain Res., 2002, 144, 122-126.

86 Q. Pankhurst, D. Hautot, N. Khan and J. Dobson, J. Alzheimers Dis. JAD, 2008, 13, 49-52. 
87 M. F. Falangola, S.-P. Lee, R. A. Nixon, K. Duff and J. A. Helpern, Neurochem. Res., 2005, 30, 201-205.

88 G. Vanhoutte, I. Dewachter, P. Borghgraef, F. Van Leuven and A. Van der Linden, Magn. Reson. Med., 2005, 53, 607-613.

89 J. Dobson, R. Bowtell, A. Garcia-Prieto and Q. Pankhurst, PLoS One, 2009, 4, e5431.

90 H. L. McConnell, D. L. Schwartz, B. E. Richardson, R. L. Woltjer, L. L. Muldoon and E. A. Neuwelt, Nanomedicine Nanotechnol. Biol. Med., 2016, 12, 1535-1542.

91 B. J. McCullough, O. Kolokythas, J. H. Maki and D. E. Green, J. Magn. Reson. Imaging, 2013, 37, 1476-1479.

92 J. L. Winer, P. E. Kim, M. Law, C. Y. Liu and M. L. J. Apuzzo, World Neurosurg., 2011, 75, 626-637.

93 M. H. Schwenk, Pharmacotherapy, 2010, 30, 70-79.

94 B. S. Spinowitz, A. T. Kausz, J. Baptista, S. D. Noble, R. Sothinathan, M. V. Bernardo, L. Brenner and B. J. G. Pereira, J. Am. Soc. Nephrol., 2008, 19, 1599-1605.

95 FDA, Drug Safety and Availability - FDA Drug Safety Communication, http:/www.fda.gov/Drugs/DrugSafety/ucm440138. htm, accessed February 3, 2017.

96 L. Sampaio, P. Linhares and J. Fonseca, Neuroradiol. J., 2017, 0, 1-8.

97 R. Chamberlain, T. M. Wengenack, J. F. Poduslo, M. Garwood and C. R. Jack, Curr. Med. Imaging Rev., 2011, 7, 3-7.

98 Y. Z. Wadghiri, D. M. Hoang, T. Wisniewski and E. M. Sigurdsson, Methods Mol. Biol., 2012, 849, 435-451.

99 H. Scholtzova, Y. Z. Wadghiri, M. Douadi, E. M. Sigurdsson, Y.-S. Li, D. Quartermain, P. Banerjee and T. Wisniewski, J. Neurosci. Res., 2008, 86, 2784-2791.

100 F. Yasuno, H. Kazui, N. Morita, K. Kajimoto, M. Ihara, A. Taguchi, A. Yamamoto, K. Matsuoka, M. Takahashi, J. Nakagawara, H. Iida, T. Kishimoto and K. Nagatsuka, Neuroimage Clin., 2016, 13, 209-214.

101 A. Ajetunmobi, A. Prina-Mello, Y. Volkov, A. Corvin and D. Tropea, Prog. Neurobiol., 2014, 123, 18-36.

102 Y. H. Bae and K. Park, J. Controlled Release, 2011, 153, 198-205.

103 J. Huang, X. Zhong, L. Wang, L. Yang and H. Mao, Theranostics, 2012, 2, 86-102.

104 M. Auffan, W. Achouak, J. Rose, M.-A. Roncato, C. Chanéac, D. T. Waite, A. Masion, J. C. Woicik, M. R. Wiesner and J.-Y. Bottero, Environ. Sci. Technol., 2008, 42, 6730-6735.

105 V. S. Periasamy, J. Athinarayanan, M. Alhazmi, K. A. Alatiah and A. A. Alshatwi, Environ. Toxicol., 2016, 31, 901-912.

106 X. Zhu, S. Tian and Z. Cai, PLoS One, 2012, 7, e46286.

107 S. Tenzer, D. Docter, S. Rosfa, A. Wlodarski, J. Kuharev, A. Rekik, S. K. Knauer, C. Bantz, T. Nawroth, C. Bier, J. Sirirattanapan, W. Mann, L. Treuel, R. Zellner, M. Maskos, H. Schild and R. H. Stauber, ACS Nano, 2011, 5, 7155-7167.

108 S. Tenzer, D. Docter, J. Kuharev, A. Musyanovych, V. Fetz, R. Hecht, F. Schlenk, D. Fischer, K. Kiouptsi, C. Reinhardt, K. Landfester, H. Schild, M. Maskos, S. K. Knauer and R. H. Stauber, Nat. Nanotechnol., 2013, 8, 772-781.
109 D. Walczyk, F. B. Bombelli, M. P. Monopoli, I. Lynch and K. A. Dawson, J. Am. Chem. Soc., 2010, 132, 5761-5768.

110 J. Kasper, M. I. Hermanns, C. Bantz, O. Koshkina, T. Lang, M. Maskos, C. Pohl, R. E. Unger and C. J. Kirkpatrick, Arch. Toxicol., 2012, 87, 1053-1065.

111 C. Bantz, O. Koshkina, T. Lang, H.-J. Galla, C. J. Kirkpatrick, R. H. Stauber and M. Maskos, Beilstein J. Nanotechnol., 2014, 5, 1774-1786.

112 N. B. Shah, G. M. Vercellotti, J. G. White, A. Fegan, C. R. Wagner and J. C. Bischof, Mol. Pharmaceutics, 2012, 9, 2146-2155.

113 V. Forest and J. Pourchez, Nano Today, 2016, 11, 700-703.

114 M. Mahmoudi, N. Bertrand, H. Zope and O. C. Farokhzad, Nano Today, 2016, 11, 817-832.

115 M. Muthiah, I.-K. Park and C.-S. Cho, Biotechnol. Adv., 2013, 31, 1224-1236.

116 K. Park, J. Controlled Release, 2010, 142, 147-148.

117 V. Estrada, N. Brazda, C. Schmitz, S. Heller, H. Blazyca, R. Martini and H. W. Müller, Neurobiol. Dis., 2014, 67, 165-179.

118 A. O. Koob, J. M. Colby and R. B. Borgens, J. Biol. Eng., 2008, 2, 9.

119 B. Li, X. Zhang, J. Yang, Y. Zhang, W. Li, C. Fan and Q. Huang, Int. J. Nanomed., 2014, 4697.

120 K. R. Chaudhari, M. Ukawala, A. S. Manjappa, A. Kumar, P. K. Mundada, A. K. Mishra, R. Mathur, J. Mönkkönen and R. S. R. Murthy, Pharm. Res., 2011, 29, 53-68.

121 M. P. Leal, S. Rivera-Fernández, J. M. Franco, D. Pozo, J. M. de la Fuente and M. L. García-Martín, Nanoscale, 2015, 7, 2050-2059.

122 D. L. J. Thorek, A. K. Chen, J. Czupryna and A. Tsourkas, Ann. Biomed. Eng., 2006, 34, 23-38.

123 U. Schroeder, P. Sommerfeld, S. Ulrich and B. A. Sabel, J. Pharm. Sci., 1998, 87, 1305-1307.

124 W.-J. Hsieh, C.-J. Liang, J.-J. Chieh, S.-H. Wang, I.-R. Lai, J.-H. Chen, F.-H. Chang, W.-K. Tseng, S.-Y. Yang, C.-C. Wu and Y.-L. Chen, Int. J. Nanomed., 2012, 7, 2833-2842.

125 W. Jiang, H. C. Yang, S. Y. Yang, H. E. Horng, J. C. Hung, Y. C. Chen and C.-Y. Hong, J. Magn. Magn. Mater., 2004, 283, 210-214.

126 C. D. Tran, S. Duri, A. Delneri and M. Franko, J. Hazard. Mater., 2013, 252-253, 355-366.

127 E. K. Agyare, K. M. Jaruszewski, G. L. Curran, J. T. Rosenberg, S. C. Grant, V. J. Lowe, S. Ramakrishnan, A. K. Paravastu, J. F. Poduslo and K. K. Kandimalla, J. Controlled Release, 2014, 185, 121-129.

128 T. Neuberger, B. Schöpf, H. Hofmann, M. Hofmann and B. von Rechenberg, J. Magn. Magn. Mater., 2005, 293, 483-496.

129 G. Prabha and V. Raj, J. Biomed. Mater. Res., Part B, 2016, 104, 808-816.

130 T. K. Saha, H. Ichikawa and Y. Fukumori, Carbohydr. Res., 2006, 341, 2835-2841.

131 I. V. Pylypchuk, D. Kołodyńska, M. Kozioł and P. P. Gorbyk, Nanoscale Res. Lett., 2016, 11, 168.

132 C. Sanjai, S. Kothan, P. Gonil, S. Saesoo and W. Sajomsang, Carbohydr. Polym., 2014, 104, 231-237. 
133 W. Sun, J. Yang, J. Zhu, Y. Zhou, J. Li, X. Zhu, M. Shen, G. Zhang and X. Shi, Biomater. Sci., 2016, 4, 1422-1430.

134 L. E. W. LaConte, N. Nitin, O. Zurkiya, D. Caruntu, C. J. O'Connor, X. Hu and G. Bao, J. Magn. Reson. Imaging, 2007, 26, 1634-1641.

135 S. Tong, S. Hou, Z. Zheng, J. Zhou and G. Bao, Nano Lett., 2010, 10, 4607-4613.

136 F. Hajesmaeelzadeh, S. Shanehsazzadeh, C. Grüttner, F. J. Daha and M. A. Oghabian, Iran. J. Basic Med. Sci., 2016, 19, 166-171.

137 B. Nottelet, V. Darcos and J. Coudane, Eur. J. Pharm. Biopharm., 2015, 97(Part B), 350-370.

138 M. Swierczewska, H. S. Han, K. Kim, J. H. Park and S. Lee, Adv. Drug Delivery Rev., 2016, 99(Part A), 70-84.

139 M. Longmire, P. L. Choyke and H. Kobayashi, Nanomedicine, 2008, 3, 703-717.

140 H. G. Rennke, Y. Patel and M. A. Venkatachalam, Kidney Int., 1978, 13, 278-288.

141 E. Sadauskas, H. Wallin, M. Stoltenberg, U. Vogel, P. Doering, A. Larsen and G. Danscher, Part. Fibre Toxicol., 2007, 4, 10.

142 H. S. Choi, W. Liu, P. Misra, E. Tanaka, J. P. Zimmer, B. I. Ipe, M. G. Bawendi and J. V. Frangioni, Nat. Biotechnol., 2007, 25, 1165-1170.

143 E. Kuntz and H.-D. Kuntz, Hepatology, Principles and Practice - History, Morphology, Biochemistry, Diagnostics, Clinic, Therapy, Springer Berlin Heidelberg, 2006, 2nd edn, vol. 3.

144 E. S. Glazer, C. Zhu, A. N. Hamir, A. Borne, C. S. Thompson and S. A. Curley, Nanotoxicology, 2011, 5, 459-468.

145 M. Semmler-Behnke, W. G. Kreyling, J. Lipka, S. Fertsch, A. Wenk, S. Takenaka, G. Schmid and W. Brandau, Small, 2008, 4, 2108-2111.

146 X. Zhang, Int. J. Nanomed., 2010, 5, 771-781.

147 D. J. Begley, Pharmacol. Ther., 2004, 104, 29-45.

148 Y. Serlin, I. Shelef, B. Knyazer and A. Friedman, Semin. Cell Dev. Biol., 2015, 38, 2-6.

149 N. J. Abbott, A. A. K. Patabendige, D. E. M. Dolman, S. R. Yusof and D. J. Begley, Neurobiol. Dis., 2010, 37, 13-25.

150 C. C. Visser, L. H. Voorwinden, D. J. A. Crommelin, M. Danhof and A. G. de Boer, Pharm. Res., 2004, 21, 761-769.

151 J. Herz and P. Marschang, Cell, 2003, 112, 289-292.

152 R. Deane, S. Du Yan, R. K. Submamaryan, B. LaRue, S. Jovanovic, E. Hogg, D. Welch, L. Manness, C. Lin, J. Yu, H. Zhu, J. Ghiso, B. Frangione, A. Stern, A. M. Schmidt, D. L. Armstrong, B. Arnold, B. Liliensiek, P. Nawroth, F. Hofman, M. Kindy, D. Stern and B. Zlokovic, Nat. Med., 2003, 9, 907-913.

153 R. Deane, Z. Wu and B. V. Zlokovic, Stroke, 2004, 35, 2628-2631.

154 D. Stern, S. Du Yan, S. Fang Yan and A. Marie Schmidt, Adv. Drug Delivery Rev., 2002, 54, 1615-1625.

155 L. Y. Di Marco, A. Venneri, E. Farkas, P. C. Evans, A. Marzo and A. F. Frangi, Neurobiol. Dis., 2015, 82, 593-606.
156 Z. Zhao, A. R. Nelson, C. Betsholtz and B. V. Zlokovic, Cell, 2015, 163, 1064-1078.

157 H. M. Wisniewski, A. W. Vorbrodt and J. Wegiel, Ann. N. Y. Acad. Sci., 1997, 826, 161-172.

158 M. Ueno, Y. Chiba, K. Matsumoto, R. Murakami, R. Fujihara, M. Kawauchi, H. Miyanaka and T. Nakagawa, Neuropathology, 2016, 36, 115-124.

159 L. O. Sillerud, N. O. Solberg, R. Chamberlain, R. A. Orlando, J. E. Heidrich, D. C. Brown, C. I. Brady, T. A. Vander Jagt, M. Garwood and D. L. Vander Jagt, J. Alzheimers Dis. JAD, 2013, 34, 349-365.

160 J. Yang, Y. Zaim Wadghiri, D. Minh Hoang, W. Tsui, Y. Sun, E. Chung, Y. Li, A. Wang, M. de Leon and T. Wisniewski, NeuroImage, 2011, 55, 1600-1609.

161 C. Nicholson, P. Kamali-Zare and L. Tao, Comput. Visualization Sci., 2011, 14, 309-325.

162 E. Syková and C. Nicholson, Physiol. Rev., 2008, 88, 1277-1340.

163 E. A. Nance, G. F. Woodworth, K. A. Sailor, T.-Y. Shih, Q. Xu, G. Swaminathan, D. Xiang, C. Eberhart and J. Hanes, Sci. Transl. Med., 2012, 4, 149 ra119.

164 H.-K. Zeng, Q.-S. Wang, Y.-Y. Deng, W.-Q. Jiang, M. Fang, C.-B. Chen and X. Jiang, BMC Neurosci., 2010, 11, 153.

165 J. F. Poduslo and G. L. Curran, J. Neurochem., 1996, 66, 1599-1609.

166 F. Hervé, N. Ghinea and J.-M. Scherrmann, AAPS J., 2008, 10, 455-472.

167 J. F. Poduslo, T. M. Wengenack, G. L. Curran, T. Wisniewski, E. M. Sigurdsson, S. I. Macura, B. J. Borowski and C. R. Jack Jr., Neurobiol. Dis., 2002, 11, 315-329.

168 E. M. Sigurdsson, Y. Z. Wadghiri, L. Mosconi, J. A. Blind, E. Knudsen, A. Asuni, H. Scholtzova, W. H. Tsui, Y. Li, M. Sadowski, D. H. Turnbull, M. J. de Leon and T. Wisniewski, Neurobiol. Aging, 2008, 29, 836-847.

169 G. Bort, S. Catoen, H. Borderies, A. Kebsi, S. Ballet, G. Louin, M. Port and C. Ferroud, Eur. J. Med. Chem., 2014, 87, 843-861.

170 B. Matharu, N. Spencer, F. Howe and B. Austen, Neuropeptides, 2015, 53, 63-70.

171 N. Serna, M. V. Céspedes, P. Saccardo, Z. Xu, U. Unzueta, P. Álamo, M. Pesarrodona, A. Sánchez-Chardi, M. Roldán, R. Mangues, E. Vázquez, A. Villaverde and N. FerrerMiralles, Nanomed. Nanotechnol. Biol. Med., 2016, 12, 1241-1251.

172 E. Ansciaux, C. Burtea, S. Laurent, D. Crombez, D. Nonclercq, L. Vander Elst and R. N. Muller, Contrast Media Mol. Imaging, 2015, 10, 211-224.

173 C. Zhang, X. Wan, X. Zheng, X. Shao, Q. Liu, Q. Zhang and Y. Qian, Biomaterials, 2014, 35, 456-465.

174 J. Chang, Y. Jallouli, M. Kroubi, X. Yuan, W. Feng, C. Kang, P. Pu and D. Betbeder, Int. J. Pharm., 2009, 379, 285-292.

175 J. Chang, A. Paillard, C. Passirani, M. Morille, J.-P. Benoit, D. Betbeder and E. Garcion, Pharm. Res., 2011, 29, 1495-1505.

176 Y. Cui, Q. Xu, P. K.-H. Chow, D. Wang and C.-H. Wang, Biomaterials, 2013, 34, 8511-8520. 
177 H. Piraux, J. Hai, P. Verbeke, N. Serradji, S. Ammar, R. Losno, N.-T. Ha-Duong, M. Hémadi and J.-M. El Hage Chahine, Biochim. Biophys. Acta, Gen. Subj., 2013, 1830, 4254-4264.

178 G. D. Vitaliano, F. Vitaliano, J. D. Rios, P. F. Renshaw and M. H. Teicher, PLoS One, 2012, 7, e35821.

179 Y. Huang, B. Zhang, S. Xie, B. Yang, Q. Xu and J. Tan, ACS Appl. Mater. Interfaces, 2016, 8, 11336-11341.

180 J. Kreuter, Adv. Drug Delivery Rev., 2001, 47, 65-81.

181 J. Kreuter, P. Ramge, V. Petrov, S. Hamm, S. E. Gelperina, B. Engelhardt, R. Alyautdin, H. von Briesen and D. J. Begley, Pharm. Res., 2003, 20, 409-416.

182 C.-F. Lien, É. Molnár, P. Toman, J. Tsibouklis, G. J. Pilkington, D. C. Górecki and E. Barbu, Biomacromolecules, 2012, 13, 1067-1073.

183 J. J. Heynekamp, W. M. Weber, L. A. Hunsaker, A. M. Gonzales, R. A. Orlando, L. M. Deck and D. L. Vander Jagt, J. Med. Chem., 2006, 49, 7182-7189.

184 S. S. Karuppagounder, J. T. Pinto, H. Xu, L. H. Chen, M. F. Beal and G. E. Gibson, Neurochem. Int., 2009, 54, 111-118.

185 J. Shin, R. M. Anisur, M. K. Ko, G. H. Im, J. H. Lee and I. S. Lee, Angew. Chem., Int. Ed., 2009, 48, 321-324.

186 T.-L. Ha, H. J. Kim, J. Shin, G. H. Im, J. W. Lee, H. Heo, J. Yang, C. M. Kang, Y. S. Choe, J. H. Lee and I. S. Lee, Chem. Commun., 2011, 47, 9176-9178.

187 J.-H. Kim, T. L. Ha, G. H. Im, J. Yang, S. W. Seo, I. S. Lee and J. H. Lee, NeuroReport, 2013, 24, 16-21.

188 J.-H. Kim, T. L. Ha, G. H. Im, J. Yang, S. W. Seo, J. J. Chung, S. Y. Chae, I. S. Lee and J. H. Lee, NeuroReport, 2014, 25, 211-218.

189 Y. Z. Wadghiri, E. M. Sigurdsson, M. Sadowski, J. I. Elliott, Y. Li, H. Scholtzova, C. Y. Tang, G. Aguinaldo, M. Pappolla, K. Duff, T. Wisniewski and D. H. Turnbull, Magn. Reson. Med., 2003, 50, 293-302.

190 E. M. Sigurdsson, H. Scholtzova, P. D. Mehta, B. Frangione and T. Wisniewski, Am. J. Pathol., 2001, 159, 439-447.

191 L. Larbanoix, C. Burtea, S. Laurent, F. Van Leuven, G. Toubeau, L. V. Elst and R. N. Muller, Neurobiol. Aging, 2010, 31, 1679-1689.

192 L. Larbanoix, C. Burtea, E. Ansciaux, S. Laurent, I. Mahieu, L. Vander Elst and R. N. Muller, Peptides, 2011, 32, 1232-1243.

193 G. Le Duc, S. Roux, A. Paruta-Tuarez, S. Dufort, E. Brauer, A. Marais, C. Truillet, L. Sancey, P. Perriat, F. Lux and O. Tillement, Cancer Nanotechnol., 2014, 5, 1-14.

194 M. Plissonneau, J. Pansieri, L. Heinrich-Balard, J.-F. Morfin, N. Stransky-Heilkron, P. Rivory, P. Mowat, M. Dumoulin, R. Cohen, É. Allémann, É. Tóth, M. J. Saraiva, C. Louis, O. Tillement, V. Forge, F. Lux and C. Marquette, J. Nanobiotechnol., 2016, 14, 60.

195 D. J. Hayne, S. Lim and P. S. Donnelly, Chem. Soc. Rev., 2014, 43, 6701-6715.

196 W. E. Klunk, H. Engler, A. Nordberg, Y. Wang, G. Blomqvist, D. P. Holt, M. Bergström, I. Savitcheva, G.-F. Huang, S. Estrada, B. Ausén, M. L. Debnath,
J. Barletta, J. C. Price, J. Sandell, B. J. Lopresti, A. Wall, P. Koivisto, G. Antoni, C. A. Mathis and B. Långström, Ann. Neurol., 2004, 55, 306-319.

197 R. Vandenberghe, K. Van Laere, A. Ivanoiu, E. Salmon, C. Bastin, E. Triau, S. Hasselbalch, I. Law, A. Andersen, A. Korner, L. Minthon, G. Garraux, N. Nelissen, G. Bormans, C. Buckley, R. Owenius, L. Thurfjell, G. Farrar and D. J. Brooks, Ann. Neurol., 2010, 68, 319-329.

198 A. F. Martins, J.-F. Morfin, C. F. G. C. Geraldes and É. Tóth, JBIC, J. Biol. Inorg. Chem., 2013, 19, 281-295.

199 M. Ono, H. Watanabe, R. Watanabe, M. Haratake, M. Nakayama and H. Saji, Bioorg. Med. Chem. Lett., 2011, 21, 117-120.

200 L. Rejc, J. Fabris, A. Adrović, M. Kasunič and A. Petrič, Tetrahedron Lett., 2014, 55, 1218-1221.

201 J. R. Barrio, N. Satyamurthy, S.-C. Huang, A. Petrič, G. W. Small and V. Kepe, Acc. Chem. Res., 2009, 42, 842-850.

202 J. Zhou, H. Fa, W. Yin, J. Zhang, C. Hou, D. Huo, D. Zhang and H. Zhang, Mater. Sci. Eng., C, 2014, 37, 348-355.

203 D. Zhang, H.-B. Fa, J.-T. Zhou, S. Li, X.-W. Diao and W. Yin, Clin. Radiol., 2015, 70, 74-80.

204 M. Garcia-Alloza, L. A. Borrelli, A. Rozkalne, B. T. Hyman and B. J. Bacskai, J. Neurochem., 2007, 102, 1095-1104.

205 L. Baum, C. W. K. Lam, S. K.-K. Cheung, T. Kwok, V. Lui, J. Tsoh, L. Lam, V. Leung, E. Hui, C. Ng, J. Woo, H. F. K. Chiu, W. B. Goggins, B. C.-Y. Zee, K. F. Cheng, C. Y. S. Fong, A. Wong, H. Mok, M. S. S. Chow, P. C. Ho, S. P. Ip, C. S. Ho, X. W. Yu, C. Y. L. Lai, M.-H. Chan, S. Szeto, I. H. S. Chan and V. Mok, J. Clin. Psychopharmacol., 2008, 28, 110-113.

206 N. Brondino, S. Re, A. Boldrini, A. Cuccomarino, N. Lanati, F. Barale and P. Politi, Sci. World J., 2014, 2014(2014), e174282.

207 S. M. Vithanarachchi and M. J. Allen, Chem. Commun., 2013, 49, 4148-4150.

208 R. Patil, P. R. Gangalum, S. Wagner, J. Portilla-Arias, H. Ding, A. Rekechenetskiy, B. Konda, S. Inoue, K. L. Black, J. Y. Ljubimova and E. Holler, Macromol. Biosci., 2015, 15, 1212-1217.

209 K. K. Cheng, P. S. Chan, S. Fan, S. M. Kwan, K. L. Yeung, Y.-X. J. Wáng, A. H. L. Chow, E. X. Wu and L. Baum, Biomaterials, 2015, 44, 155-172.

210 C. B. Cowan, G. L. Coté and T. A. Good, Biomaterials, 2008, 29, 3408-3414.

211 D. Patel, J. Henry and T. Good, Biochim. Biophys. Acta, Gen. Subj., 2006, 1760, 1802-1809.

212 D. A. Patel, J. E. Henry and T. A. Good, Brain Res., 2007, 1161, 95-105.

213 A. Kakio, S. Nishimoto, K. Yanagisawa, Y. Kozutsumi and K. Matsuzaki, J. Biol. Chem., 2001, 276, 24985-24990.

214 H. Kouyoumdjian, D. C. Zhu, M. H. El-Dakdouki, K. Lorenz, J. Chen, W. Li and X. Huang, ACS Chem. Neurosci., 2013, 4, 575-584.

215 H.-S. Hsieh, R. Wu and C. T. Jafvert, Environ. Sci. Technol., 2014, 48, 11330-11336.

216 L. Rubio, N. El Yamani, A. Kazimirova, M. Dusinska and R. Marcos, Environ. Res., 2016, 146, 185-190. 
217 S. I. L. Gomes, D. Hansen, J. J. Scott-Fordsmand and M. J. B. Amorim, Environ. Pollut., 2015, 199, 49-55.

218 C. H. da Costa, F. Perreault, A. Oukarroum, S. P. Melegari, R. Popovic and W. G. Matias, Sci. Total Environ., 2016, 565, 951-960.

219 A. Platel, R. Carpentier, E. Becart, G. Mordacq, D. Betbeder and F. Nesslany, J. Appl. Toxicol., 2016, 36, 434-444.

220 J. Khalili Fard, S. Jafari and M. A. Eghbal, Adv. Pharm. Bull., 2015, 5, 447-454.

221 M. A. Voinov, J. O. S. Pagán, E. Morrison, T. I. Smirnova and A. I. Smirnov, J. Am. Chem. Soc., 2011, 133, 35-41.

222 S. Lu, W. Zhang, R. Zhang, P. Liu, Q. Wang, Y. Shang, M. Wu, K. Donaldson and Q. Wang, Part. Fibre Toxicol., 2015, $12,5$.

223 G. Ciofani, S. Danti, D. D’Alessandro, S. Moscato and A. Menciassi, Biochem. Biophys. Res. Commun., 2010, 394, 405-411.

224 S. H. Doak, S. M. Griffiths, B. Manshian, N. Singh, P. M. Williams, A. P. Brown and G. J. S. Jenkins, Mutagenesis, 2009, 24, 285-293.

225 N. A. Monteiro-Riviere, A. O. Inman and L. W. Zhang, Toxicol. Appl. Pharmacol., 2009, 234, 222-235.

226 F. Joris, D. Valdepérez, B. Pelaz, S. J. Soenen, B. B. Manshian, W. J. Parak, S. C. De Smedt and K. Raemdonck, J. Nanobiotechnol., 2016, 14, 69.

227 S. Sharifi, S. Behzadi, S. Laurent, M. L. Forrest, P. Stroeve and M. Mahmoudi, Chem. Soc. Rev., 2012, 41, 2323-2343.

228 J. Athinarayanan, V. S. Periasamy, M. A. Alsaif, A. A. Al-Warthan and A. A. Alshatwi, Cell Biol. Toxicol., 2014, 30, 89-100.

229 S. Quignard, G. Mosser, M. Boissière and T. Coradin, Biomaterials, 2012, 33, 4431-4442.

230 P. L. Santo-Orihuela, M. L. Foglia, A. M. Targovnik, M. V. Miranda and M. F. Desimone, Curr. Pharm. Biotechnol., 2016, 17, 465-470.

231 M. Yao, L. He, D. J. McClements and H. Xiao, J. Agric. Food Chem., 2015, 63, 8044-8049.

232 A. Kroll, C. Dierker, C. Rommel, D. Hahn, W. Wohlleben, C. Schulze-Isfort, C. Göbbert, M. Voetz, F. Hardinghaus and J. Schnekenburger, Part. Fibre Toxicol., 2011, 8, 9.

233 B. J. Teubl, C. Schimpel, G. Leitinger, B. Bauer, E. Fröhlich, A. Zimmer and E. Roblegg, J. Hazard. Mater., 2015, 286, 298-305.

234 M. Yu, S. Huang, K. J. Yu and A. M. Clyne, Int. J. Mol. Sci., 2012, 13, 5554-5570.

235 X.-D. Zhang, H.-Y. Wu, D. Wu, Y.-Y. Wang, J.-H. Chang, Z.-B. Zhai, A.-M. Meng, P.-X. Liu, L.-A. Zhang and F.-Y. Fan, Int. J. Nanomed., 2010, 5, 771-781.

236 B. Wang, W. Feng, M. Zhu, Y. Wang, M. Wang, Y. Gu, H. Ouyang, H. Wang, M. Li, Y. Zhao, Z. Chai and H. Wang, J. Nanopart. Res., 2008, 11, 41-53.

237 S. Linse, C. Cabaleiro-Lago, W.-F. Xue, I. Lynch, S. Lindman, E. Thulin, S. E. Radford and K. A. Dawson, Proc. Natl. Acad. Sci. U. S. A., 2007, 104, 8691-8696.

238 V. L. Colvin and K. M. Kulinowski, Proc. Natl. Acad. Sci. U. S. A., 2007, 104, 8679-8680.
239 C. Cabaleiro-Lago, F. Quinlan-Pluck, I. Lynch, S. Lindman, A. M. Minogue, E. Thulin, D. M. Walsh, K. A. Dawson and S. Linse, J. Am. Chem. Soc., 2008, 130, 15437-15443.

240 W. Wu, X. Sun, Y. Yu, J. Hu, L. Zhao, Q. Liu, Y. Zhao and Y. Li, Biochem. Biophys. Res. Commun., 2008, 373, 315-318.

241 M. H. Ahmed, J. A. Byrne and T. E. Keyes, Mater. Sci. Eng., C, 2014, 39, 227-234.

242 M. Mahmoudi, M. P. Monopoli, M. Rezaei, I. Lynch, F. Bertoli, J. J. McManus and K. A. Dawson, ChemBioChem, 2013, 14, 568-572.

243 M. Mahmoudi, O. Akhavan, M. Ghavami, F. Rezaee and S. M. A. Ghiasi, Nanoscale, 2012, 4, 7322-7325.

244 S. Mirsadeghi, R. Dinarvand, M. H. Ghahremani, M. R. Hormozi-Nezhad, Z. Mahmoudi, M. J. Hajipour, F. Atyabi, M. Ghavami and M. Mahmoudi, Nanoscale, 2015, 7, 5004-5013.

245 M. Ghavami, M. Rezaei, R. Ejtehadi, M. Lotfi, M. A. Shokrgozar, B. Abd Emamy, J. Raush and M. Mahmoudi, ACS Chem. Neurosci., 2012, 4, 375-378.

246 T. Grobner, Nephrol., Dial., Transplant., 2006, 21, 1104-1108.

247 L. Telgmann, M. Sperling and U. Karst, Anal. Chim. Acta, 2013, 764, 1-16.

248 M. A. Perazella, Clin. J. Am. Soc. Nephrol., 2007, 2, 200-202.

249 J. G. Penfield and R. F. Reilly, Nat. Clin. Pract. Nephrol., 2007, 3, 654-668.

250 X. Wang, Y. Feng, T. Ke, M. Schabel and Z.-R. Lu, Pharm. Res., 2005, 22, 596-602.

251 J. L. Abraham and C. Thakral, Eur. J. Radiol., 2008, 66, 200-207.

252 T. P. Snutch, Encyclopedia of Neuroscience, Academic Press, Oxford, 2009, pp. 427-441.

253 R. L. Winslow, M. A. Walker and J. L. Greenstein, Wiley Interdiscip. Rev.: Syst. Biol. Med., 2016, 8, 37-67.

254 Y. Liu and N. Zhang, Biomaterials, 2012, 33, 5363-5375.

255 J. Y. Chang and L.-Z. Liu, Mol. Brain Res., 1999, 68, 22-28.

256 A. B. Bowman, G. F. Kwakye, E. Herrero Hernández and M. Aschner, J. Trace Elem. Med. Biol., 2011, 25, 191-203.

257 E. J. Martinez-Finley, C. E. Gavin, M. Aschner and T. E. Gunter, Free Radical Biol. Med., 2013, 62, 65-75.

258 B. Michalke and K. Fernsebner, J. Trace Elem. Med. Biol., 2014, 28, 106-116.

259 C.-C. Huang, N.-H. Khu and C.-S. Yeh, Biomaterials, 2010, 31, 4073-4078.

260 K. A. M. Ahmed, Q. Zeng, K. Wu and K. Huang, J. Solid State Chem., 2010, 183, 744-751.

261 K. H. Bae, K. Lee, C. Kim and T. G. Park, Biomaterials, 2011, 32, 176-184.

262 D. Pan, A. H. Schmieder, S. A. Wickline and G. M. Lanza, Tetrahedron, 2011, 67, 8431-8444.

263 A. Nel, Science, 2005, 308, 804-806.

264 A. Nel, T. Xia, L. Mädler and N. Li, Science, 2006, 311, 622-627.

265 M.-T. Zhu, B. Wang, Y. Wang, L. Yuan, H.-J. Wang, M. Wang, H. Ouyang, Z.-F. Chai, W.-Y. Feng and Y.-L. Zhao, Toxicol. Lett., 2011, 203, 162-171.

266 H. Wu, J.-J. Yin, W. G. Wamer, M. Zeng and Y. M. Lo, J. Food Drug Anal., 2014, 22, 86-94. 
267 G. Jarockyte, E. Daugelaite, M. Stasys, U. Statkute, V. Poderys, T.-C. Tseng, S.-H. Hsu, V. Karabanovas and R. Rotomskis, Int. J. Mol. Sci., 2016, 17, 1193.

268 M. Mahmoudi, M. A. Shokrgozar, S. Sardari, M. K. Moghadam, H. Vali, S. Laurent and P. Stroeve, Nanoscale, 2011, 3, 1127-1138.

269 X. Feng, A. Chen, Y. Zhang, J. Wang, L. Shao and L. Wei, Int. J. Nanomed., 2015, 10, 4321-4340.

270 H. S. Sharma and A. Sharma, CNS Neurol. Disord.: Drug Targets, 2012, 11, 65-80.

271 F. A. Cupaioli, F. A. Zucca, D. Boraschi and L. Zecca, Prog. Neurobiol., 2014, 119, 20-38.

272 R. Chen, D. Ling, L. Zhao, S. Wang, Y. Liu, R. Bai, S. Baik, Y. Zhao, C. Chen and T. Hyeon, ACS Nano, 2015, 9, 12425-12435.

$273 \mathrm{~J}$. Wu, T. Ding and J. Sun, Neurotoxicology, 2013, 34, 243-253.

274 C. Olchowy, K. Cebulski, M. Łasecki, R. Chaber, A. Olchowy, K. Kałwak and U. Zaleska-Dorobisz, PLoS One, 2017, 12, e0171704.

275 FDA, Drug Safety and Availability - FDA Drug Safety Communication, https:/www.fda.gov/Drugs/DrugSafety/ucm559007. htm, accessed July 20, 2017.

276 I. P. Grudzinski, M. Bystrzejewski, M. A. Cywinska, A. Kosmider, M. Poplawska, A. Cieszanowski and A. Ostrowska, J. Nanopart. Res., 2013, 15, 1-18.

277 N. Lewinski, V. Colvin and R. Drezek, Small, 2008, 4, 26-49.

278 X. Mao, J. Xu and H. Cui, Wiley Interdiscip. Rev.: Nanomed. Nanobiotechnol., 2016, 8, 814-841.

279 T. Kim, E. Momin, J. Choi, K. Yuan, H. Zaidi, J. Kim, M. Park, N. Lee, M. T. McMahon, A. Quinones-Hinojosa, J. W. M. Bulte, T. Hyeon and A. A. Gilad, J. Am. Chem. Soc., 2011, 133, 2955-2961.

280 X. Li, W. Zhao, X. Liu, K. Chen, S. Zhu, P. Shi, Y. Chen and J. Shi, Acta Biomater., 2016, 30, 378-387.

281 P. Ayers and L. Warrington, Nutr. Clin. Pract., 2008, 23, 122-127.

282 M. Rohrer, H. Bauer, J. Mintorovitch, M. Requardt and H.-J. Weinmann, Invest. Radiol., 2005, 40, 715-724.

283 Y. Shen, F. L. Goerner, C. Snyder, J. N. Morelli, D. Hao, D. $\mathrm{Hu}, \mathrm{X} . \mathrm{Li}$ and V. M. Runge, Invest. Radiol., 2015, 50, 330-338.

284 D. Yoo, J.-H. Lee, T.-H. Shin and J. Cheon, Acc. Chem. Res., 2011, 44, 863-874.

285 J. Choi, J.-H. Lee, T.-H. Shin, H.-T. Song, E. Y. Kim and J. Cheon, J. Am. Chem. Soc., 2010, 132, 11015-11017.

286 M. Yang, L. Gao, K. Liu, C. Luo, Y. Wang, L. Yu, H. Peng and W. Zhang, Talanta, 2015, 131, 661-665.

287 K. Cheng, M. Yang, R. Zhang, C. Qin, X. Su and Z. Cheng, ACS Nano, 2014, 8, 9884-9896.
288 B. H. McDonagh, G. Singh, S. Hak, S. Bandyopadhyay, I. L. Augestad, D. Peddis, I. Sandvig, A. Sandvig and W. R. Glomm, Small, 2016, 12, 301-306.

289 C. Laske, H. R. Sohrabi, S. M. Frost, K. López-de-Ipiña, P. Garrard, M. Buscema, J. Dauwels, S. R. Soekadar, S. Mueller, C. Linnemann, S. A. Bridenbaugh, Y. Kanagasingam, R. N. Martins and S. E. O'Bryant, Alzheimer's Dementia, 2015, 11, 561-578.

290 H. Amiri, K. Saeidi, P. Borhani, A. Manafirad, M. Ghavami and V. Zerbi, ACS Chem. Neurosci., 2013, 4, 1417-1429.

291 B. Ruozi, D. Belletti, F. Pederzoli, P. Veratti, F. Forni, M. A. Vandelli and G. Tosi, Curr. Med. Chem., 2014, 21, 4169-4185.

292 P. O. Larsen and M. von Ins, Scientometrics, 2010, 84, 575-603.

293 S. G. Antimisiaris, Clin. Lipidol., 2014, 9, 477-481.

294 J. A. Loureiro, B. Gomes, G. Fricker, M. A. N. Coelho, S. Rocha and M. C. Pereira, Colloids Surf., B, 2016, 145, 8-13.

295 R. Zhang, Y. Li, B. Hu, Z. Lu, J. Zhang and X. Zhang, Adv. Mater., 2016, 28, 6345-6352.

296 D. Cabuzu, A. Cirja, R. Puiu and A. M. Grumezescu, Curr. Top. Med. Chem., 2015, 15, 1605-1613.

297 M. Mahmoudi, M. A. Sahraian, M. A. Shokrgozar and S. Laurent, ACS Chem. Neurosci., 2011, 2, 118-140.

298 M. Mahmoudi, S. Sant, B. Wang, S. Laurent and T. Sen, Adv. Drug Delivery Rev., 2011, 63, 24-46.

299 V. Nandwana, S.-R. Ryoo, S. Kanthala, M. De, S. S. Chou, P. V. Prasad and V. P. Dravid, ACS Appl. Mater. Interfaces, 2016, 8, 6953-6961.

300 H.-Z. Jia, W. Wang, D.-W. Zheng, X. Wang, W.-Y. Yu, S.-Y. Li, R.-X. Zhuo, Y.-F. Zhao, J. Feng and X.-Z. Zhang, ACS Appl. Mater. Interfaces, 2016, 8, 6784-6789.

301 S. Richard, A. Saric, M. Boucher, C. Slomianny, F. Geffroy, S. Mériaux, Y. Lalatonne, P. X. Petit and L. Motte, ACS Chem. Biol., 2016, 11, 2812-2819.

302 H. J. Kwon, M.-Y. Cha, D. Kim, D. K. Kim, M. Soh, K. Shin, T. Hyeon and I. Mook-Jung, ACS Nano, 2016, 10, 2860-2870.

303 R. Shukla, V. Bansal, M. Chaudhary, A. Basu, R. R. Bhonde and M. Sastry, Langmuir, 2005, 21, 10644-10654.

304 K. S. Kim, D. Lee, C. G. Song and P. M. Kang, Nanomedicine, 2015, 10, 2709-2723.

305 C. Lasagna-Reeves, D. Gonzalez-Romero, M. A. Barria, I. Olmedo, A. Clos, V. M. Sadagopa Ramanujam, A. Urayama, L. Vergara, M. J. Kogan and C. Soto, Biochem. Biophys. Res. Commun., 2010, 393, 649-655.

306 Q. Zhang, S. S. Rajan, K. M. Tyner, B. J. Casey, C. K. Dugard, Y. Jones, A. M. Paredes, C. S. Clingman, P. C. Howard and P. L. Goering, J. Biomed. Mater. Res., Part B, 2016, 104, 1032-1042. 